\title{
TSG-6: a multifunctional protein with anti-inflammatory and tissue-protective properties
}

DOI:

10.1016/j.matbio.2018.01.011

\section{Document Version}

Accepted author manuscript

Link to publication record in Manchester Research Explorer

\section{Citation for published version (APA):}

Day, A., \& Milner, C. (2018). TSG-6: a multifunctional protein with anti-inflammatory and tissue-protective properties. Matrix Biology. https://doi.org/10.1016/j.matbio.2018.01.011

\section{Published in:}

Matrix Biology

\section{Citing this paper}

Please note that where the full-text provided on Manchester Research Explorer is the Author Accepted Manuscript or Proof version this may differ from the final Published version. If citing, it is advised that you check and use the publisher's definitive version.

\section{General rights}

Copyright and moral rights for the publications made accessible in the Research Explorer are retained by the authors and/or other copyright owners and it is a condition of accessing publications that users recognise and abide by the legal requirements associated with these rights.

\section{Takedown policy}

If you believe that this document breaches copyright please refer to the University of Manchester's Takedown Procedures [http://man.ac.uk/04Y6Bo] or contact uml.scholarlycommunications@manchester.ac.uk providing relevant details, so we can investigate your claim.

\section{OPEN ACCESS}




\title{
TSG-6: a multifunctional protein with
}

\section{anti-inflammatory and tissue-protective properties}

\author{
Anthony J Day and Caroline M Milner ${ }^{b}$ \\ aWellcome Trust Centre for Cell-Matrix Research, Division of Cell-Matrix Biology and Regenerative \\ Medicine, School of Biological Sciences, Faculty of Biology, Medicine and Health, University of \\ Manchester, Michael Smith Building, Oxford Road, Manchester M13 9PT, UK. Email: \\ anthony.day@manchester.ac.uk \\ ${ }^{b}$ Division of Cell-Matrix Biology and Regenerative Medicine, School of Biological Sciences, Faculty \\ of Biology, Medicine and Health, University of Manchester, Michael Smith Building, Oxford Road, \\ Manchester M13 9PT, UK. Email: caroline.milner@manchester.ac.uk
}

Corresponding author: Anthony J. Day. Tel: +44 (0)161 275 1495;

email: anthony.day@manchester.ac.uk

Declaration of Interests: The authors are developing Link_TSG6 (the recombinant Link module from human TSG-6) as a biological drug and have a 3 granted patents (EP2001499, JP5346216, US9066908) and a patent pending in the US (14/481841, published in 2015) on the use of TSG6/Link_TSG6 for osteoarthritis and osteoporosis. AJD has stock in Temple Therapeutics, LLC (Framingham, MA, USA) resulting from his (now terminated) consultancy to this company, which is focused on MSC- and TSG-6-based therapeutics. AJD and CMM have no other potential conflicts of interest. 
Abstract. Tumor necrosis factor- (TNF) stimulated gene-6 (TSG-6) ${ }^{1}$ is an inflammation-associated secreted protein that has been implicated as having important and diverse tissue protective and anti-inflammatory properties, e.g. mediating many of the immunomodulatory and beneficial activities of mesenchymal stem/stromal cells. TSG-6 is constitutively expressed in some tissues, which are either highly metabolically active or subject to challenges from the environment, perhaps providing protection in these contexts. The diversity of its functions are dependent on the binding of TSG-6 to numerous ligands, including matrix molecules such as glycosaminoglycans, as well as immune regulators and growth factors that themselves interact with these linear polysaccharides. It is becoming apparent that TSG-6 can directly affect matrix structure and modulate the way extracellular signalling molecules interact with matrix. In this review, we focus mainly on the literature for TSG-6 over the last 10 years, summarizing its expression, structure, ligand-binding properties, biological functions and highlighting TSG-6's potential as a therapeutic for a broad range of disease indications.

Keywords (6): TSG-6, hyaluronan, matrix reorganisation, chemokines, MSCs, inflammation.

${ }^{1}$ Abbreviations. AHR: airway hyperresponsiveness; AM: amniotic membrane; BAL: bronchoalveolar lavages; BMP: bone morphogenetic protein; COC: cumulus-oocyte complex; CS: chondroitin sulphate; DCs: dendritic cells; DS: dermatan sulphate; ECs: endothelial cells; FN: fibronectin; GAG: glycosaminoglycan; GFAP: glial fibrillary acid protein; HA: hyaluronan; HC: heavy chain (also known as SHAP: serum-derived HA-binding protein); HC•HA: HA chain with HCs covalently attached; HC•TSG-6: covalent complex of HC with TSG-6; HS: heparan sulfate; I $\alpha$ : inter- $\alpha-$ inhibitor; IL: interleukin; LPS: lipopolysaccharide; MSCs: mesenchymal stem/stromal cells; OA: osteoarthritis; Pal: pre- $\alpha$-inhibitor; PG: proteoglycan; PTX3: pentraxin-3; RA: rheumatoid arthritis; T1D; Type-1 diabestes; TGF $\beta$ : tumor growth factor- $\beta$; TNF: tumor necrosis factor; TK: tissue kallikrein; TSG-6: TNF-stimulated gene-6 (also known as TNFAIP6: TNF $\alpha$-induced protein-6); TSP: thrombospondin. 


\section{Introduction}

TSG-6 is the secreted protein product of the TNF-stimulated gene-6 [1] that while constitutively expressed in a few tissues is generally upregulated wherever there is inflammation. For the most part TSG-6 exhibits anti-inflammatory and tissue protective properties, but has been implicated as sometimes playing a role in disease pathology, for example, in the lung. While being made by a broad range of cell types, it was the finding that TSG-6 is produced by mesenchymal stem/stromal cells (MSCs) in response to inflammatory signals [2], and that it mediates many of their immunomodulatory and reparative activities [3], which has led to a wealth of publications on the therapeutic effects of this intriguing molecule across a wide range of disease models.

TSG-6 is a relatively small protein, with a molecular mass of only $\sim 35-38 \mathrm{kDa}$, being mainly composed of two modular domains (Figure 1). Given TSG-6's size, it has a surprisingly large number of activities, including the modulation of immune and stromal cell function and its contribution to extracellular matrix formation, mechanics and remodelling (Figure 2). It is the ability of TSG-6 to regulate matrix organization, and to control the association of matrix molecules with cell surface receptors and with extracellular signalling factors (e.g. chemokines), that likely underlies its diverse functional repertoire. In this regard, TSG-6 interacts with a large array of ligands (Table 1), such as glycosaminoglycans (GAGs), proteoglycan (PG) core proteins and other matrix components, and binds directly to multiple chemokines and bone morphogenetic proteins (BMPs). One particularly unusual function of TSG-6 is its role as an enzyme that catalyses the covalent modification of the non-sulfated GAG hyaluronan (HA) with so-called heavy chains (HCs) from the inter- $\alpha$-inhibitor ( $|\alpha|)$ family of proteoglycans. This TSG-6-mediated process, which results in the formation of $\mathrm{HC} \cdot \mathrm{HA}$ complexes, is essential for mammalian ovulation and fertilisation, and also occurs in many other contexts (e.g. inflammation) where HC•HAs either confer tissue protection or contribute to pathological processes.

In this review article we will cover recent insights into the sites and contexts of TSG-6 expression, its structure and ligand-binding properties, and how these together underpin its diverse biology and therapeutic potential at a molecular and cellular level. Here we will mostly focus on publications from the last 10 years, where earlier literature is covered in detail in our previous reviews [4-6]. 


\section{TSG-6 Expression in Physiology and Pathology}

\subsection{Constitutive TSG-6 expression}

While it is well established that TSG-6 expression is upregulated during inflammation $[4,5,7]$, there are a number of locations where TSG-6 is now known to be expressed constitutively (Table 2), including amniotic membrane (AM) [8], brain and the central nervous system [9], lung [10], endocrine pancreas [11-14], spleen [13] and skin [15]. These tissues fall into two broad categories: those where there is a high basal level of metabolic activity (e.g. brain and the islets of Langerhans in pancreas) or those that provide a barrier to the environment (i.e. being constantly bombarded with exogenous challenges) and/or play a role in host immune defence (e.g. AM, lung, skin). This is consistent with TSG-6's role as an endogenous protector of tissues, which to date has been studied mostly in the context of inflammation and disease processes.

In the case of human AM, TSG-6 immunostaining is associated with epithelial cells, stromal cells and the stromal matrix, and there is also strong evidence that $|\alpha|$ and HA are both present in AM [8], thus providing an explanation for the formation of $\mathrm{HC} \cdot \mathrm{HA}$ complexes shown previously to be constitutively present in this location [16]. Recently it has been found that TSG-6 is constitutively expressed by MSCs obtained from AM, where the TSG-6 protein was able to reduce the production of neutrophil extracellular traps by bone marrow derived neutrophils [17]; this may contribute to the anti-inflammatory functions of AM [18].

TSG- 6 is expressed by CD44 $/ \mathrm{GFAP}^{+}$astrocytes in the brains and spinal cords of mature rats but not during embryonic development [9]. In this context TSG-6 has been implicated in astrocyte maturation since there are fewer astrocytes in the brains of TSG-6 null mice. There is considerable upregulation of TSG-6 expression following spinal cord injury, where the protein is associated with the glial scar, potentially playing a role in formation and stabilization of this HA-rich matrix. TSG-6 is present at low levels in human airway secretions, but is significantly increased in smokers, likely due to smoke-induced inflammation [10]; TSG-6 is also present in the bronchoalveolar lavages (BAL) of asthma patients being further upregulated in response to allergen challenge. Recent work has strongly implicated TSG-6 in the development of ozoneinduced airway hyperresponsiveness (AHR) in the mouse, where the TSG-6 knockout mouse is protected from the detrimental effects of ozone exposure [19]. However, in other contexts TSG-6 
has been shown to mediate protective effects in the lung; e.g. lipopolysaccharide- (LPS) and bleomycin-induced lung injury [20-22].

There is constitutive expression of TSG-6 in the islets of Langerhans in human and murine pancreas, where it is produced by the pancreatic $\alpha$ and $\beta$ cells $[12,13]$ and perhaps stored in secretory granules [13]. Interestingly, there is a progressive loss of TSG-6 expression in animal models of type-1 diabetes (T1D) during disease progression [11,14], and TSG-6 is also decreased in human diabetic islets during development of T1D and during autoimmune insulitis [13]. While there is a reduction of TSG-6 expression by endocrine cells during diabetes/insulitis there is TSG-6 production by infiltrating $\mathrm{CD}^{+}$and $\mathrm{CD} 11 \mathrm{c}^{+}$leukocytes $[11,13]$. However, these descriptive data provide little insight into whether the loss of TSG-6 contributes directly to the progression of T1D and further work is necessary to determine if TSG-6 deficiency predisposes to diabetes.

TSG-6 is also constitutively expressed in human skin with TSG-6 immunoreactivity being much more intense in the epidermis compared to the dermis [15]; TSG-6 staining was also seen in hair follicles and sebaceous glands. The amount of TSG-6 was significantly reduced in the epidermis of keloid scars compared to unscarred skin. TSG-6 mRNA has been found to be constitutively expressed by human dermal fibroblasts in culture [23]. In this study there was a decrease in both constitutive TSG-6 expression, and after tumor growth factor- $\beta$ (TGF $\beta$ ) stimulation, with increasing donor age; this led to reduced fibroblast to myofibroblast differentiation which would be expected to give rise to impaired wound healing.

In addition to the constitutive expression of TSG-6 by stromal cells, it is also constitutively present in the secretory granules of human neutrophils and mouse mast cells $[24,25]$. In non-activated neutrophils there is TSG-6 mRNA production and storage of the protein in lactoferrin-positive 'specific' granules, along with the TSG-6 ligand pentraxin-3 (PTX3), where TSG-6 protein is released (and its expression upregulated) in response to LPS. Mast cells also contain TSG-6, which is present in heparin-containing secretory granules, being released on mast cell degranulation [25]; the TSG-6 is stored in association with the tryptases mMCP-6 and mMCP-7, where these likely form ternary complexes with TSG-6 and heparin. In vitro experiments indicated that ternary complexes could also be formed between TSG-6, the tryptases and HA. Whether TSG-6 inhibits tryptase enzymatic activity is not known. 


\subsection{Inducible TSG-6 expression}

With the exception of the cells and tissues described above TSG-6 is not in general constitutively expressed in 'normal' adult tissues, being induced during some physiological processes (such as ovulation and cervical ripening), or in response to inflammatory mediators.

\subsubsection{TSG-6 expression in ovulation}

TSG-6 is expressed during murine ovulation by the cumulus cells that surround the oocyte [26], having a critical role in forming the HA-rich cumulus matrix that is required for successful ovulation and fertilisation [27-29]; a process called cumulus-oocyte complex (COC) expansion. Here TSG-6 expression is induced by prostaglandins, and mice that are deficient in cyclooxygenase- 2 or the prostaglandin E2 receptor are infertile [30]. Moreover, deletion of the TSG-6 gene or the inhibition/disruption of TSG-6-mediated $\mathrm{HC} \cdot \mathrm{HA}$ formation leads to infertility due to defective expansion of the cumulus matrix [27-29]. A recent study found that a high fat diet in both lean and obese mice led to an impairment in the estrous cycle and reduced expression of TSG-6 along with other genes that are critical to normal ovulation [31]. There is also evidence that TSG-6 is expressed during ovulation in other mammals (e.g. cows, horses, pigs and sheep), but here it is less clear whether TSG-6's transferase activity is essential or not [32-35].

\subsubsection{TSG-6 expression by MSCs}

One of the most exciting findings on TSG-6 over the last 10 years is that it is expressed by MSCs and mediates many of their immunomodulatory and tissue protective properties. This was discovered by Darwin Prockop's group when human bone marrow-derived MSCs were injected systemically in murine myocardial infarction, showing that TSG-6 expression was upregulated by the cells that became trapped in microemboli in the lung, i.e. in response to the inflammatory milieu present in this disease model [2]. Treatment with MSCs significantly reduced the infarct size, even though they did not engraft into the heart tissue. TSG-6 secreted by the MSCs was shown to be mediating this therapeutic effect, since it was abolished by siRNA knockdown in the MSCs and because intravenous administration of rhTSG-6 protein was almost as effective. Following on from this discovery, TSG-6 expressed by MSCs and recombinant TSG-6 have been found to be efficacious in a wide range of disease models (see Section 5 and Table 3). 
MSCs in monolayer culture do not constitutively express TSG-6 but mRNA is greatly upregulated in response to TNF [2], whereas when the MSCs are in 3D spheroids they express TSG-6 (mRNA and protein) at very high levels in the absence of stimulation [36]. In addition to bone marrow derived MSCs, TSG-6 is also expressed by adipose-derived MSCs [37-39], dedifferentiated fat cells [40] and umbilical cord perivascular cells [41-43], mediating their protective effects (see Table 2).

\subsubsection{TSG-6 expression in response to inflammation and injury}

TSG-6 production is induced by inflammatory mediators (e.g. interleukin-1 (IL-1), LPS, TGF $\beta$ and TNF) in a wide range of leukocytes, stromal cells and tissues (covered in [4-6] for papers up to 2007); however, which pro-inflammatory factor(s) induces expression is highly cell-type dependent. In addition to neutrophils (see above), TSG-6 is also expressed by other leukocytes, including monocyte-derived dendritic cells (DCs) in response to LPS [24], and there is a marked upregulation of TSG-6 mRNA (>500-fold) on phorbol ester-induced differentiation of THP1 monocytes to macrophages [44]; macrophages also express TSG-6 in response to LPS [24] and TNF [45]. As described in Section 4.5, TSG-6 is induced by IL-1, IL-6 and TNF in osteoclasts and their monocytic precursors, acting as an autocrine regulator to supress bone breakdown [45].

As described previously, TSG-6 is upregulated by inflammatory cytokines in many different stromal cell types including endothelial cells (ECs), airway and kidney epithelial cells, fibroblasts and vascular smooth muscle cells (VSMCs) [4-6]. More recently TSG-6 expression has been found to be induced in human airway submucosal gland cells by IL-1 and TNF [10] and TSG-6 protein is associated with VSMCs and perivascular cells in human abdominal aortic aneurysms [46]. TSG-6 mRNA is also expressed by human endometrium during the proliferative and secretory phases of the menstrual cycle [47] and during endometriosis [48].

TSG-6 is well established to be associated with human arthritis, where it is produced by chondrocytes and synoviocytes (see [4]). The protein has been quantitated in the synovial fluids of patients with rheumatoid arthritis (RA) and osteoarthritis (OA) as well as other arthritides (e.g. pyrophosphate arthritis) [45]; TSG-6 levels in synovial fluid appear to correlate with disease progression in human OA [49] and in experimental murine RA [25]. In OA, TSG-6 is upregulated in chondrocytes in areas of damaged articular cartilage [50-53], and based on studies in the mouse it 
is very rapidly induced in the joint after surgical destabilisation [54]; consistent with this TSG-6 is detectable in synovial fluid after joint trauma in humans [55]. At present it is unclear whether TSG6 production is good or bad in the context of OA (and other musculoskeletal pathologies). However, TSG-6-- mice, while having no obvious phenotype in the absence of challenge, get much more severe joint damage in a model of inflammatory arthritis, which is due in part to the loss of TSG-6's anti-inflammatory effect on neutrophil migration [56].

Considering the beneficial effects of TSG-6 treatment in many disease models (Section 5), it seems reasonable to suggest that the upregulation of TSG-6 expression during acute inflammation serves to protect tissues from the damaging and unwanted side effects of the immune response. However, in some chronic inflammatory settings, it is probable that TSG-6 production contributes to pathology. Further research is clearly needed to understand the role of endogenous TSG-6 expression during disease processes.

\section{TSG-6 Domain Organization and Structural Information}

The TSG-6 protein is composed of a short N-terminal segment, followed by contiguous Link and CUB modules, and a C-terminal region (Figure 1); the amino acid sequence is very highly conserved between vertebrate species, for example, with human and mouse TSG-6 having 93\% identity. While there is no structural information available for the $\mathrm{N}$ - or $\mathrm{C}$-terminal regions the tertiary structures of the Link and CUB modules have both been determined (Figure 1). The structure of the human Link module (Link_TSG6), a domain also found in the HA receptor CD44, was first elucidated by nuclear magnetic resonance (NMR) spectroscopy in the mid 1990s [57]. This was followed by a better quality solution structure in 2003 , where the Link module conformation was determined in the absence and presence of an $\mathrm{HA}$ octasaccharide $\left(\mathrm{HA}_{8}\right)$, demonstrating that there is a considerable conformational change in the protein on HA binding [58], as well as a stabilisation of the Link module fold [59]. The HA-bound conformation was then used in combination with other data to generate a experimentally validated model of the Link module in complex with $\mathrm{HA}_{8}[60,61]$. This is illustrated in Figure $3 \mathrm{~A}$, showing how the $\mathrm{HA}$ threads through a shallow groove and wraps round two faces of the Link module domain [61]; as described below this contributes to TSG-6's ability to profoundly alter the conformation of HA [62]. 
Comparison of the model for the Link_TSG6/HA ${ }_{8}$ complex with the CD44/HA ${ }_{8}$ crystal structure [63], reveals that although the $\mathrm{HA}$ is bound at a common binding site on the Link modules of these two proteins, the molecular details of the interactions are quite distinct $[61,64]$. The binding of TSG-6 to $\mathrm{HA}$ is mediated by a combination of ionic and aromatic ring stacking interactions $[58,60,61,64]$, whereas the CD44-HA interaction is mediated by hydrogen bonds and van der Waal's forces [63]; whilst there are two specificity pockets that accommodate HA's N-acetyl groups in the TSG-6 Link module there is only one in CD44. Together these differences likely explain the higher affinity of Link_TSG6 for HA compared to the HA-binding domain of CD44 [61]. Recently an NMR structure has also been determined for Link_TSG6 in complex with an oligosaccharide of chondroitin-4sulfate (C4S), revealing that C4S binds to the same site as HA on TSG-6 [65], explaining how C4S and HA can compete for each other's binding $[66,67]$. Surprisingly, although there is no steric reason why chondroitin-6-sulfate could not also be accommodated within the HA-binding groove, this isoform of CS binds much more poorly than C4S to Link_TSG6 (see [65]).

\section{The ligand-binding properties of TSG-6 and related functional activities}

As illustrated in Figure 2, TSG-6 has been implicated as having a broad-range of functions, where these are underpinned by its interaction with diverse ligands, including GAGs, CSPG core proteins, other matrix molecules, components of $|\alpha|$ and the related pre- $\alpha$-inhibitor $(P \alpha l)$, chemokines and growth factors. Here we will focus on ligands for which there is information that relates the interaction directly to TSG-6 function; for ligands not covered in detail in the text, further information and references can be found in Table 1.

\subsection{Interactions with glycosaminoglycans}

TSG-6 is unusual in that it binds to both sulfated and non-sulfated GAGs including chondroitin [61], C4S [65-68], dermatan sulfate (DS) [68], HA [61,62], heparan sulfate (HS) [69] and heparin $[68,69]$ (Table 1). Of these interactions the best characterized is with HA.

\subsubsection{Hyaluronan}

As described above (Section 3), we have detailed information on how HA binds to Link_TSG6, i.e. the isolated Link module domain of TSG-6 (see [61]). However, whilst this 1:1 interaction is noncooperative in nature, binding of HA to the full-length protein is cooperative (and consequently of 
higher affinity) and leads to the HA-induced oligomerization of TSG-6, where dimers and larger oligomers (likely tetramers) can directly cause crosslinking of individual HA stands (Figure 3B,C; Table 1) [62]. Here the use of surface-sensitive techniques has demonstrated that TSG-6 binding to HA has a dramatic effect on HA structure, collapsing and stiffening the HA network (Figure 3D). This structural perturbation of HA is likely due to the combined effect of crosslinking [62] and the conformational change in HA induced by TSG-6 binding (Figure 3A) [61]. This is anticipated to be of biological importance since TSG-6 has the potential to collapse/organize HA-rich matrices (in a concentration-dependent manner $[62,64])$, and thereby alter the mechanical properties and hydration state of tissues. For example, this could be relevant to HA-rich provisional matrices formed during wound healing [70]. Interestingly, the interaction of $|\alpha|$ with TSG-6 has been found to abolish TSG-6's HA-binding activity and reverse the TSG-6-mediated condensation of HA [71]; the formation of $\mathrm{HC} \cdot \mathrm{HAs}$ (and their crosslinking, e.g. by PTX3) leads to a much more hydrated and expanded HA network compared to complexes of TSG-6 and HA [72]. As described above, TSG-6 is expressed prior to ovulation where it and HA are both produced by the cumulus cells surrounding the oocyte. Thus in the early stages of ovulation TSG-6 could potentially package the HA into a dense pericellular matrix, which could then expand following lal's entry into the ovarian follicle and diffusion into the COC where the TSG-6/HA complexes are located. As described in Section 4.2 the interaction of TSG-6 with lal also leads to HC•HA formation, where TSG-6 associated with a crosslinked HA matrix retains its transferase activity $[71,72]$. In addition, given that matrix stiffness has a well-established role in cell regulation [73], TSG-6 expression (and l $\alpha$ l ingress), for example, during inflammation, could be involved in tuning the rigidity of HA-containing tissues thereby influencing cellular phenotype [62].

The association of TSG-6 with HA can also directly affect the interaction of the polysaccharide with its cell surface receptors, increasing the binding of HA to CD44 [71,74] (Figure 3D) and the lymph vessel endothelial receptor LYVE1 [75]. Both rhTSG-6 and Link_TSG6 (albeit more weakly) can enhance HA binding to CD44, whereas in the case of LYVE1 the full-length TSG-6 protein has a considerably more potent effect. This is probably due to the different crosslinking potential of rhTSG-6 and Link_TSG6 and their differential effects on HA structural perturbation [62], and because LYVE1 is very sensitive to how HA is presented [75]. LYVE1 on lymph vessel endothelial 
cells exhibits essentially no binding to HA unless the polysaccharide is in a crosslinked state. This is because LYVE1 must be in the form of a covalent dimer to bind HA, where the individual LYVE1 molecules in the dimer are thought to bind to different HA chains [76]. It is anticipated that this crosslinking mechanism of TSG-6 will also regulate the binding of HA to other receptors, such as layilin [77], but as yet this has not been studied.

These findings also illustrate that the composition of HA/protein complexes dictate whether HAreceptor interactions occur and likely determine the outcome of cellular responses. In this regard, some of TSG-6's anti-inflammatory effects (on antigen-presenting cells, macrophages and T cells) have been shown to be dependent on CD44 [78,79], and given that there is no published evidence that TSG-6 and CD44 interact directly it is reasonable to suggest that these are mediated through the enhancement of the HA-CD44 interaction. Moreover, TSG-6 can also regulate CD44-mediated rolling of leukocytes via its interaction with HA [74].

\subsubsection{Heparan sulfate and heparin}

TSG-6 interacts with heparin and HS though its Link module domain (Table 1), where the binding of Link_TSG6 and the full-length protein appear similar [69]; 2-O- and 6-O- sulfates play a more important role than $\mathrm{N}$-sulfates in the interaction [68]. The binding site for heparin/HS is on a different face of the Link module from where HA binds, and although there is no overlap in their interaction surfaces, heparin and HA can compete for binding. This is likely due to an allosteric effect, since the association with HA alters the Link module conformation [58] and affects the dynamics of amino acids implicated in the interaction with heparin $[59,80]$. Heparin also induces the dimerization of Link_TSG6 [69] (unlike HA that only promotes the oligomerization of the fulllength protein [62]) and recent biophysical work indicates that Link_TSG6 can crosslink heparin chains and lead to the condensation of a heparin film ([81], HL Birchenough, TA Jowitt and AJ Day, unpublished data). This may partially explain how Link_TSG6 is able to inhibit the binding of chemokines to HS on ECs, in addition to its direct protein-protein interactions with these immune regulators [82]; see Section 4.4. Overall, these findings suggest that TSG-6 may be able to modulate HS structure in tissues and thereby the binding of other HS-binding proteins, and that the composition of the matrix or pericellular environment is likely important in determining, for example, the relative amounts of TSG-6/HA and TSG-6/HS complexes. 
TSG-6 has been found to potentiate the anti-plasmin activity of bikunin [83], a CSPG that forms part of $|\alpha|$ and Pal (Figure 4), where this is mediated entirely by its Link module domain [84]; here Link_TSG6/rhTSG-6 may interact with both bikunin and the CS chain $[69,85]$. The binding of TSG6 to heparin (e.g. in the context of Link_TSG6) enhances its potentiation with evidence that this occurs via the formation of a ternary complex between TSG-6, heparin and bikunin [69]. These anti-plasmin activities of TSG-6 have been implicated in mediating some of its tissue protective effects, e.g. in a mouse model of myocardial infarction [2].

\subsubsection{Chondroitin sulfate and CSPG core proteins}

As described in Section 3, TSG-6 binds to C4S via its Link module domain, where the binding leads to dimerization of the recombinant Link_TSG6 protein [65]; while it is not yet known whether this is also a feature of the full-length TSG-6 (see Table 1), this is certainly feasible based on modelling. In addition to the C4S binding site described above (where the sugar interacts with the HA-binding groove), there is also a lower affinity interaction surface on the heparin-binding face of the Link module. This means that in a TSG-6 dimer there would be 4 different binding surfaces, which could lead to crosslinking of individual C4S chains and potentially a major structural reorganisation of the polysaccharide e.g. when TSG-6 is bound along a single C4S chain. This could serve to collapse CSPGs in tissues and contribute to matrix remodelling. In this regard, TSG6 can also bind through its Link module to the G1-domain of aggrecan, via a protein-protein interaction, and compete for the binding of aggrecan to HA $[53,86]$. While it has been suggested that this could block matrix assembly in OA [53] where TSG-6 is expressed $[50,52,53,87]$, another possibility is that the inhibition of aggrecan-HA binding and the collapse of its CS chains could package the aggrecan allowing it to diffuse away from the chondrocyte surface. This would promote matrix formation/repair in the cartilage interterritorial matrix; here $\mathrm{pH}$ gradients present in cartilage could further regulate this process $[67,88]$. Interestingly, there is evidence that TSG-6's competition of the aggrecan-HA interaction is regulated by $\mathrm{HC} \cdot \mathrm{HA}$ at the articular surface in $\mathrm{OA}$ [53], where these complexes are not present in the deeper zones of the tissue $[53,89]$.

\subsection{The role of TSG-6 in HC•HA formation}

\subsubsection{The structural and functional diversity of $H C \cdot H A s$}


TSG-6 has an important enzymatic function, transferring HCs from members of the lal family onto HA (Figure 4); while chondroitin also acts as a (weaker) substrate, TSG-6 is not thought to transfer HCs onto DS, or HS [90,91]. However, CS chains, including those of versican [92], amyloid precursor like protein 2 (APLP2) [44], and bikunin [93], can become modified with HCs. To date TSG-6 is the only HC transferase to have been described and therefore may have a nonredundant role in the transfer of HCs onto HA and chondroitin/CS. This activity of TSG-6 (Figure 2) has been suggested to be evolutionarily conserved in vertebrates, where, for example, the role of $\mathrm{HC} \cdot \mathrm{HA}$ complexes in inflammatory processes predates their function in stabilising the cumulus matrix during ovulation [94]. It is important to note that, given TSG-6's catalytic activity [71,95], even low levels of TSG-6 production could lead to significant amounts of HC•HA formation over time, i.e. in biological contexts where HA and $|\alpha|$ are also present.

Six HCs have been described, where only HC4 is unlikely to be able to be transferred onto HA [96]. There is growing evidence that the composition of $\mathrm{HC} \cdot \mathrm{HA}$ complexes is highly tissue and context dependent, where this likely correlates with whether they play a physiological/protective function or contribute to disease progression.

$\mathrm{HC} 1$ and $\mathrm{HC} 2$ (from $|\alpha|$ ), and $\mathrm{HC} 3$ (from $\mathrm{P \alpha l}$ ), are transferred onto HA during murine COC expansion [26] and in the synovial fluids of RA and OA patients [97-99], where TSG-6 is expressed (Section 2 and Table 2). In the periovulatory period, HC•HA complexes are crosslinked through their interactions with PTX3, an octameric protein $[100,101]$ essential for stabilising the cumulus matrix [102], via its interactions with multiple HA-bound HCs [100,103]. Direct evidence for crosslinking has been obtained by biophysical experiments in HA films, which have also revealed that the formation of $\mathrm{HC} \cdot \mathrm{HA}$ complexes and their binding to PTX3 are likely coupled and very tightly regulated [72]. While it was suggested previously that the interaction of TSG-6 with PTX3 could also serve to crosslink HA chains [102], this does not occur in the context of the fulllength TSG-6 protein [72]; Link_TSG6, which was used in the original experiments [102] is able, however, to bind simultaneously to PTX3 and HA [72]. Furthermore, our recent work has shown that cumulus expansion relies primarily on the transferase activity of TSG-6, and that its HAbinding function likely only plays a minor role [29]. 
Whilst the same 3 heavy chains ( $\mathrm{HC} 1, \mathrm{HC} 2$ and $\mathrm{HC} 3)$ are transferred onto $\mathrm{HA}$ during arthritis [97], the functions of the $\mathrm{HC} \cdot \mathrm{HA}$ complexes in this context are less certain. What is known is that the overall levels of HCs in synovial fluids correlate with RA disease severity [98], and that TSG-6's transferase activity (as a surrogate for TSG-6 levels) is prognostic of the need for joint replacement surgery in OA [49]. However, it is not clear in these contexts whether TSG-6-mediated formation of $\mathrm{HC} \cdot \mathrm{HA}$ is driving disease pathology or if this in fact counteracts disease processes/progression. In rheumatoid synovial fluids it has been found that between 3-5 HCs become attached to a single $\sim 2$ MDa HA chain and that the $\mathrm{HC} \cdot \mathrm{HA}$ complexes are more aggregated (i.e. crosslinked) compared to unmodified HA, potentially via direct interactions between HCs [99]; whether PTX3 is present or not in the complexes has not been fully established. One possibility is that crosslinking of $\mathrm{HC} \cdot \mathrm{HA}$ (whatever the mechanism) may preserve the hydrodynamic properties of the synovial fluid HA, which becomes fragmented and diluted during arthritis, and thus have a beneficial effect [104]. Interestingly, the $\mathrm{HC} \cdot \mathrm{HA}$ complexes from RA patients are more adhesive for CD44 on leukocytes compared to free HA, and thereby might support leukocyte infiltration into the inflamed synovium [105]. Although, the enhancement of leukocyte binding could clearly contribute to pathology, it is also possible that $\mathrm{HC} \cdot \mathrm{HA}$ might communicate anti-inflammatory signals, as is the case for $\mathrm{HC} \cdot \mathrm{HAs}$ produced in other contexts.

$\mathrm{HC} \cdot \mathrm{HA}$ from $\mathrm{AM}$ has been found to be potentially anti-angiogenic, anti-fibrotic and antiinflammatory $[16,106-108]$; for example being able to polarise macrophages to an M2 phenotype [107]. In this context, $|\alpha|$ and TSG-6 are constitutively expressed leading, rather surprisingly to an $\mathrm{HC} \cdot \mathrm{HA}$ that contains only $\mathrm{HC} 1$ [8]; based on the mechanism in Figure 5, it is not apparent how just $\mathrm{HC} 1$ can be transferred from lal. PTX3 is also constitutively expressed in AM, where the formation of HC1 $\mathrm{HA}$ /PTX3 complexes is thought to play a protective role during fetal development [109]; moreover, the presence of PTX3 enhances the anti-inflammatory activity of the complex. The mechanism underlying the protective properties of this type of $\mathrm{HC} \cdot \mathrm{HA}$ has only been partially elucidated [18].

Constitutive $\mathrm{HC} \cdot \mathrm{HA}$ formation is associated with murine airway epithelial cells (AECs) and human renal proximal tubular ECs, both of which make HC3•HA, through constitutively expressing $\mathrm{P} \alpha \mathrm{l}$ and TSG-6 [110]. AECs in culture assemble the HC3•HA complexes into raft-like structures on 
their ciliated apical surface that can capture and entrap leukocytes. Such leukocyte adhesive structures were also identified in the BAL fluids and on the ciliated airway epithelium of naive mice, where they have been hypothesized to play a role in host defence.

However, in other contexts, $\mathrm{HC} \cdot \mathrm{HAs}$ have been implicated as contributing to lung pathology, e.g. in cystic fibrosis [111] and in a mouse model of AHR [19]. Cystic fibrosis patients exhibited aberrant degradation of HA, which may be due to HC-mediated crosslinking, and there was also increased infiltration of leukocytes that correlated with sites where there were high levels of HC•HA [111]. In murine AHR, TSG-6 null animals were protected from the effects of ozone treatment, where this was attributed to an absence of TSG-6-mediated HC transfer [19]; TSG-6-/ mice also had attenuated AHR in a model of acute allergic pulmonary inflammation, with reduced numbers of airway eosinophils, leading to the suggestion that TSG-6's transferase activity may contribute to the development of asthma [112]; however, data from human asthma do not fully support this conclusion [113]. In all of these contexts, while it is likely that HA is modified with $\mathrm{HC} 1, \mathrm{HC} 2$, and $\mathrm{HC} 3$, further information on the compositions of the $\mathrm{HC} \cdot \mathrm{HA}$ formed (and the absence/presence of accessory proteins, such as PTX3) would be helpful in understanding how these complexes contribute to lung pathology. In this regard, while HC•HA from RA synovial fluid was pro-adhesive for leukocytes [105] HC•HA made in vitro from lal (and HA and TSG-6) was not [71], providing clear evidence that the composition of $\mathrm{HC} \cdot \mathrm{HA}$ complexes and the context of their production is important in determining their biological activities. It is also intriguing why TSG-6 should contribute to lung disease in certain contexts [19,111,112,114], but be highly protective in others [20-22].

TSG-6 has been found to be essential for TGF $\beta 1$-induced differentiation of fibroblasts to myofibroblasts, supporting the formation of a HA-rich pericellular matrix [96]. Here the production of $\mathrm{HC} \cdot \mathrm{HA}$ was implicated in stabilizing the $\mathrm{HA}$ coat and promoting the association of CD44 with the epidermal growth factor receptor, an interaction shown previously to occur in lipid rafts in an HAdependent manner [115]. HC5 (and bikunin) expression was strongly upregulated by TGF $\beta 1$ and, this along with other data, indicate that HC5 is likely to form a complex with CS•bikunin as is the case for HCs1-3 in lal/Pal [96]. Furthermore, TSG-6 was required for the incorporation of HC5 into the HA pericellular matrix, suggestive of the generation of a $\mathrm{HC} 5 \cdot \mathrm{HA}$ complex.

\subsubsection{The molecular basis of TSG-6-mediated HC•HA formation}


Figure 5 shows a schematic representation of TSG-6's role in HC•HA formation, based on the available literature (recently summarized in [29]), consisting of two sequential transesterification reactions, which are both dependent on divalent cations [95]. This is best characterised for lal, where the determination of the TSG-6 CUB module structure (Figure 5), along with other biophysical and functional analysis, has clarified the role of metal ions in mediating the formation of HC.TSG-6 (intermediates in the transfer of $\mathrm{HCs}$ onto HA) in a two step, $\mathrm{Ca}^{2+}-$ and $\mathrm{Mg}^{2+} / \mathrm{Mn}^{2+}$ dependent process [29]. However, many molecular details are still missing, including, how the initial non-covalent lal/TSG-6 complexes convert into covalent HC1•TSG-6 and HC2•TSG-6 complexes and the location of the catalytic site within TSG-6 [29]. The role of TSG-6's interaction with the CS chain of $|\alpha|$ is also unclear, however, it is likely to play some part in the formation of HC•TSG-6 [85], especially since the sulfation state of the tetrasaccharide linkage region (attaching the CS to bikunin) regulates TSG-6's transferase activity [116]. Moreover, how HA binds in the context of the HC.TSG-6 intermediates to effect transfer of HC onto HA is poorly understood. What is apparent is that the HA-binding groove utilised in free TSG-6 (see Section 3) is not used in its entirety for HA recognition by HC•TSG-6 [29,61]; while Y47 is involved, other critical HA-binding residues (i.e. Y94 and Y113 that mediate aromatic ring stacking interactions $[58,60,61]$ ), are not [29]. This is consistent with the finding that the interaction of $|\alpha|$ with TSG-6 effectively abolishes HA binding [71], suggesting that in HC.TSG-6 a new 'composite' binding site for HA is formed [29]. In addition to TSG-6 mediating the transfer of $\mathrm{HC} 1$ and $\mathrm{HC} 2$ from $|\alpha|$ onto $\mathrm{HA}$, it can also dynamically shuffle HCs between GAGs [117]. However, the transfer of HCs onto HA oligosaccharides $\left(\mathrm{HA}_{8}-\mathrm{HA}_{21}\right)$ [118] or chondroitin [91] is irreversible. This may provide a mechanism for how HCs can be removed from high molecular weight HA [118], i.e. in the context of endogenous production of HA oligomers, and with potential therapeutic applications.

The molecular basis of the transfer of other $\mathrm{HCs}$ (e.g. HC3 and HC5) onto HA is less well characterized. However, there is evidence that $|\alpha|$ or $\mathrm{HC} 2 \cdot$ bikunin containing species are required in addition to Pal and TSG-6 in the transfer of HC3 onto HA [119]. This, however, appears to be in conflict with findings in [110] since in this latter study HC3•HA could be formed in the absence of $\mathrm{HC} 1$ and $\mathrm{HC} 2$. 
As shown in Figure 5, one consequence of TSG-6-mediated HC transfer is the production of HC·CS•bikunin byproducts [95,120], which degrade over time (probably by hydrolysis) to CS•bikunin and free HC [10]. This unmasks the tissue kallikrein (TK) inhibitory activity of bikunin, which is essentially inactive in the context of I $\alpha \mid[10]$. TK is a serine protease involved in the airway inflammatory response, and bikunin was found to account for a significant proportion of the anti-TK activity in BAL from asthma sufferers after allergen challenge. Thus, this is a different mechanism by which TSG-6 can potentiate the activity of a serine protease inhibitor (distinct from that described above for plasmin [69]) and another way in which TSG-6 can mediate a protective effect.

\subsection{Interactions with matrix proteins}

In addition to the CSPGs aggrecan [86], bikunin [69] and versican [121], TSG-6 binds to several other matrix proteins, i.e. fibronectin (FN) [122], PTX3 [102,123], thrombospondin-1 (TSP1) and TSP2 [124]; see Table 1.

TSG-6 has been reported to interact with both the cell-binding and heparin-binding regions of human FN [122]; while these interactions had no effect on integrin-mediated cell adhesion, TSG-6 was found to promote FN fibrillogenesis and the interaction of FN with TSP1 (see below). This shows that TSG-6's matrix reorganising function is not limited to just GAGs. The binding of TSG-6 to FN was reported to be mediated by its CUB_C domain, where the Link module was not thought to be significantly involved (based on microtiter plate interaction assays). However, more recent studies using surface plasmon resonance have discovered that the high affinity association of TSG-6 to the cell/integrin-binding region of FN is mediated entirely through TSG-6's Link module domain ([81], HL Birchenough, TA Jowitt and AJ Day, unpublished data); the Link module also contributes to the interaction with the heparin-binding region of FN, but in this case the CUB_C domain may also be involved (Table 1). Given that CUB_C_TSG6, like rhTSG-6, was able to promote the assembly of a FN-rich matrix by fibroblasts [122], it does seem likely that this region of TSG-6 plays some role.

The Link module of TSG-6 mediates the interaction with the N-terminal domains of TSP1 and TSP2 [124]. The TSG-6-TSP1 interaction was strongly inhibited by heparin, even for mutants of Link_TSG6 that have greatly impaired heparin-binding activity, indicating that TSG-6 binds to the heparin-binding surface on TSP1. As noted above, TSG-6 enhances the binding of TSP1 with FN 
[122]; in this case only the full-length TSG-6 exhibited this interaction, with neither the recombinant CUB_C_TSG6 or Link_TSG6 having any effect. These findings indicate that TSG-6 can directly crosslink FN and TSP1 (i.e. via non-overlapping binding sites on TSG-6), which may be important in the regulation of matrix assembly at tissue locations where TSP1 is expressed, e.g. during inflammation and wound repair. Interestingly, TSP1 was also found to be a positive regulator of TSG-6's HC transferase activity, such that this protein could serve to enhance HC $\cdot H A$ production (and HA crosslinking) at sites of inflammation [124]. Given that TSP1 is a trimeric protein it is also possible that complexes of TSP1 and TSG-6 could directly crosslink HA by an alternative mechanism [104], however, there are no data currently to support this.

As described above, although Link_TSG6 can interact simultaneously with PTX3 and HA the fulllength protein (rhTSG-6) doesn't support the crosslinking of HA [72]. TSG-6 binds to the N-terminal domain of PTX3, which is also the site where fibroblast growth factor-2 (FGF2) binds with similar affinity [123]. FGF2 is a potent inducer of angiogenesis, where this is inhibited by PTX3. TSG-6 was found to inhibit the interaction between FGF2 and PTX3, restoring FGF2's pro-angiogenic activity [123]; while this is likely mediated through the binding of TSG-6 to PTX3, the interaction of TSG-6 with FGF2 (A Inforzato and AJ Day, unpublished data) may also be involved. It should be noted that although TSG-6 is not a promoter of angiogenesis per se, it does inhibit the inhibition of this process. In this regard, TSG-6 has been suggested to act as a biological rheostat to tune the level of neovascularization [123], e.g. at inflammatory sites where TSG-6 and PTX3 are both expressed.

\subsection{Interactions with chemokines}

An important recent discovery is that TSG-6 can bind to a broad range of chemokines, making TSG-6 the first soluble chemokine-binding protein to be identified in mammals $[82,125]$. To date, TSG-6 has been found to interact with 10 chemokines (mediated via a direct protein-protein interaction) including members of both CC and CXC chemokine sub-families. As summarized in Table 1, available data indicate that TSG-6 has a general role in inhibiting the binding of chemokines to HS, thus regulating their presentation on ECs and their interactions with matrix HSPGs, as well as to other matrix molecules such as type-1 collagen [125]. Here TSG-6 binds to the heparin/HS-binding site on the chemokines, blocking their interactions with GAGs, which is 
mediated by the Link module of TSG-6 using an interaction surface (yet to be defined) that does not overlap with its own heparin/HS binding function.

The interaction of CXCL8 with TSG-6, and the inhibition of its binding with endothelial HS, has provided a mechanism [125] that explains the potent inhibitory activity of TSG-6 on neutrophil transendothelial migration [83,84,126]; where the full-length rhTSG-6 and Link_TSG6 have essentially identical activities [84]. This anti-inflammatory function has been implicated as contributing to the protective or efficacious therapeutic effects of TSG-6 in numerous in vivo models of disease $[2,56,78,127-132]$; see Table 3 .

Given that TSG-6 binds to other chemokines [82,125], which have receptors on a wide range of different white blood cell populations, it is reasonable to speculate that TSG-6 will likely play an important role in regulating the migration and activity of many different types of leukocyte subsets; e.g. CCR5-, CCR7- and CXCR4-mediated transendothelial migration [82]. In this regard, TSG-6 has already been implicated in the regulation of dendritic cells, macrophages, monocytes, and $\mathrm{T}$ cells $[2,22,42,79,128,133,134]$. Here it should be noted that while TSG- 6 inhibited chemotaxis of neutrophils, albeit much more weakly than its effect on transendothelial migration [125], there was no such effect for the other chemokines investigated (i.e. CCL5, CCL19, CCL21 and CXCL12) [82]. Thus, TSG-6 may not modulate chemokine-receptor interactions, but rather the availability of chemokines at the EC surface or in the matrix.

\subsection{Interactions with bone morphogenetic proteins and RANKL}

As shown in Table 1, TSG-6 interacts with 7 different BMPs and with RANKL [135-137], where these proteins have a role in osteogenesis or bone breakdown, respectively. Of the BMPs, the functional consequences of their interaction with TSG-6 have only been investigated for BMP2, i.e. where TSG-6 inhibits the BMP2-mediated differentiation of MSCs to osteoblasts $[136,137]$. Consistent with this, TSG- $6^{-/}$mice were found to have significantly higher bone density than controls, suggestive of a role for TSG-6 in bone homeostasis [137]. Interestingly, TSG-6 has recently been found to be secreted by MSCs in response to BMP2, where this suppresses MAPKdependent inflammatory signalling in a macrophage cell line [138]. There is somewhat conflicting data on what region of TSG-6 mediates the interaction with BMP2. The studies in [136] showed that when the Link module was deleted the TSG-6 protein was no longer able to inhibit 
osteoblastogenesis, whereas deletion of the CUB module had a less deleterious effect, implicating the Link module as the major mediator of the interaction. However, comparisons of rhTSG-6, CUB_C_TSG6 and Link_TSG6 indicated that both the CUB_C and Link module domains are likely involved in the interaction with BMP2 [137]; similar data were obtained for BMP13 and BMP14. Further work is needed to explore this further.

In the case of RANKL, a composite binding site involving both Link and CUB_C domains seems likely [137]. Importantly, TSG-6 inhibits RANKL-induced osteoclast-mediated bone resorption, where TSG-6 affects osteoclast activity rather than osteoclast differentiation $[45,137]$. These findings suggest that TSG-6 is not acting simply as a decoy receptor (i.e. like osteoprotegerin), since if this were the case then osteoclastogenesis would also be inhibited; furthermore, osteoprotegerin and rhTSG-6 (but not Link_TSG6) are synergistic in their anti-resorptive activities [45]. Thus it is not clear whether TSG-6's inhibitory activity is dependent on the RANKL-TSG-6 interaction. As noted in Section 2, TSG-6 is expressed by both pre- and mature osteoclasts in response to IL-1, IL-6 or TNF, identifying TSG-6 as an autocrine regulator of osteoclast function; TSG-6 also suppresses the resorptive activity of osteoclasts differentiated from synovial fluid macrophages following TNF treatment, where this also induces TSG-6 expression.

\section{The immunomodulatory and tissue protective activities of TSG-6}

The discovery in 2009 that TSG-6 is secreted by MSCs [2] has given rise to a large number of publications demonstrating that this protein mediates many of the immunomodulatory and reparative effects of these stem/stromal cells [3]. Here, rather than providing a comprehensive review of the literature, we have identified representative studies to illustrate the range of disease models in which TSG-6 has been found to mediate a therapeutic effect; summarized in Table 3. In this regard, TSG-6 has been found to be efficacious in cardiovascular disease (e.g. atherosclerosis/restenosis [139-141] and myocardial infarction [2]), dermatology and wound healing (e.g. burn-induced inflammation [42], hypertrophic scaring [142] and gingival wounding [143]), eye indications (e.g. corneal allogenic transplant rejection [128], corneal wounding [127], and age-related macular degeneration [134,144]), gastroenterology (e.g. colitis [39,131] and peritonitis [78]), metabolic disease (e.g. liver disease [145] and type-1 diabetes [79]), 
musculoskeletal conditions (e.g. rheumatoid arthritis [146,147]), neurology (e.g. traumatic brain injury $[130,148])$ and respiratory disease (e.g. acute lung injury $[21,22,149,150])$. Many of these studies follow the same experimental rationale as in [2], such that the efficacies of MSCs are shown to be diminished/abolished by siRNA knockdown of TSG-6 and/or that treatment with the recombinant full length protein has a similar (or least significant) therapeutic activity. Importantly, the level of TSG-6 production has been identified as a biomarker that can be used to predict the efficacy of human MSCs as modulators of sterile inflammation [149].

The effects of TSG-6 are broad ranging (see Table 3) where these include the suppression of inflammation, the reduction of tissue injury and disease indices, and the enhancement of healing and repair processes. For instance, TSG-6 enhanced autophagy and reduced apoptosis of hepatocytes in a model of chronic liver damage [151] and had anti-fibrotic activities in acute liver injury [145], cutaneous wound healing [133] and following vein graft surgery where it limited restenosis [141]. Moreover, TSG-6 inhibited collagen expression and hypertrophic scaring in a rabbit ear model [142], but, conversely increased the production of collagens in atherosclerotic plaques of ApoE null mice [140], where it has been suggested to lead to plaque stabilization, e.g. protecting against stroke $[139,140]$. TSG-6 also modulates matrix turnover by supressing MMP production [130,131], where this is likely mediated through TSG-6's anti-inflammatory effects. For example, it reduced MMP9 expression by ECs and neutrophils in a murine model of traumatic brain injury, thereby protecting the blood-brain barrier; in this study TSG-6 protein administration improved memory function [130].

In addition to affecting the activity of stromal cells in tissues TSG-6 also has many immunomodulatory functions. For example, TSG-6 has a potent inhibitory effect on the migration of neutrophils that has been observed in numerous model systems [2,56,78,127-132]; see Table 3 . As described in Section 4.4., the mechanism of action has been identified, where TSG-6 binds to the neutrophil chemoattractant, CXCL8, and regulates its binding to HSPGs on ECs [125]. TSG-6 also mediates immunosuppressive effects on other cells of the innate immune system. For example, it inhibits TNF secretion by activated macrophages $[36,133]$, where it has been

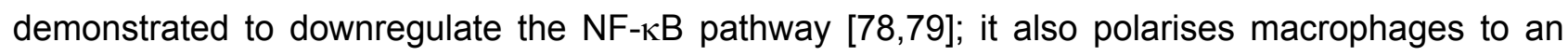
anti-inflammatory M2 phenotype [22]. Furthermore, TSG-6 increased the production of regulatory T 
cells (Tregs) $[79,131]$, e.g. via the promotion of a tolerogenic phenotype in antigen presenting cells, and supressed the development of a Th1-mediated immune response [79]. In this regard, TSG-6 delayed the onset of type-1 diabetes in a spontaneous mouse model. However, the role of TSG-6 in regulating immune crosstalk and the underlying molecular mechanisms are yet to be fully explored.

As noted above (Section 4.1.1.) some of the effects of TSG-6 are likely to be mediated via its regulation of CD44-HA interactions [78,79,152-154]. However, TSG-6's activity as a multifunctional chemokine-binding protein (Section 4.4. $[82,125]$ ) and its role in $\mathrm{HC} \cdot \mathrm{HA}$ formation (Section 4.2), where these complexes mediate therapeutic effects [18], might also be important in many of these contexts. Further work is needed to determine how the various ligand-binding activities of TSG-6 (Table 1) contribute to its anti-inflammatory and tissue protective effects.

The wealth of data on the therapeutic potential of TSG-6 in experimental models (Table 3) opens up significant opportunities for the use of TSG-6 in the treatment of human disease. Much work is needed to translate these exciting findings to the clinic.

\section{Figure Legends.}

Figure 1. TSG-6 domain organization and structure. Amino acid numbering is shown for the human protein, where the domain organization is based on the structural information available for the Link and CUB modules [29,58,59]. Recombinant human TSG-6 (rhTSG-6), made in a Drosophila expression system [155], corresponds to the mature protein sequence. CUB_C_TSG6 (made as a recombinant protein in E. coli [122]) corresponds to the human CUB module along with the 28 amino acid C-terminal segment ('C' in schematic). Recombinant human Link_TSG6 (also expressed in E. coli) corresponds to the Link module domain and a 4-amino acid sequence from the N-terminus of the CUB module. Structures are depicted as ribbon diagrams for the Link (left) and CUB (right) modules, which are colored from blue $\left(\mathrm{N}\right.$-terminus; $\left.\mathrm{NH}_{2}\right)$ to red $(\mathrm{C}$-terminus; $\mathrm{COOH}$ ). The structure shown for the Link module (left) was determined by NMR spectroscopy on Link_TSG6 (pdb 107b [58]) and is composed of $2 \alpha$-helices and $2 \beta$-sheets (each made of $3 \beta$ strands), where the 4 conserved cysteine residues form 2 disulfide bonds. The CUB module structure (right) was derived from X-ray crystallography on CUB_C_TSG6 (pdb 2WNO [29]) and 
has a Jelly Roll fold based on $2 \beta$-sheets formed from 4 or $5 \beta$-strands. This structure belongs to the metal ion-binding subtype of CUB modules [156], where it contains a single $\mathrm{Ca}^{2+}$ ion (cyan sphere) and two conserved disulphide bridges [29]. While the C-terminal peptide of the CUB_C domain was present in the crystals, this part of the structure was not visible, presumably because it is conformationally flexible. There are no structural data for the $\mathrm{N}$-terminal segment (labelled ' $\mathrm{N}$ ' on schematic).

Figure 2. TSG-6 is a multi-functional protein. The functional properties of TSG-6 can be grouped into 4 main categories (red ovals): cell regulation; immune regulation; matrix organization, and the formation of $\mathrm{HC} \cdot \mathrm{HA}$ complexes. Each of these can be further subdivided into specific properties (green ovals); see text for details and supporting references.

Figure 3. TSG-6 modulates HA structure and receptor binding. A) The refined model of the Link_TSG6/HA 8 complex showing how the HA chain bends round the Link module [61]. B) Model of a TSG-6/HA $A_{8}$ complex based on small angle X-ray scattering of rhTSG-6 in the presence of an HA octasaccharide [62]; the binding of rhTSG-6 to HA via its Link module domain (blue) induces dimerization of TSG-6 (and the formation of higher oligomers), which is thought to be mediated via a protein-protein interaction between CUB_C domains (green) [62]. C) Schematic showing how HA-induced dimerization of TSG-6 could result in crosslinking of the HA polysaccharide, where multiple HA chains are linked together by TSG-6. D) Biophysical experiments have demonstrated that rhTSG-6, and to a lesser extent Link_TSG6 (not shown), causes the condensation (and stiffening) of HA films, i.e. where HA chains are grafted onto a sensor chip through their reducing termini [62]. E) The binding of rhTSG-6 (and Link_TSG6; not shown) to HA enhances the interaction of HA with cell surface CD44 (as determined by flow cytometry with CD44 ${ }^{+}$cells), which is presumed to be through the crosslinked HA promoting CD44 clustering and receptor activation $[71,74]$. Data in (D) and (E) are taken from [62] and [71], respectively.

Figure 4. TSG-6 mediates covalent transfer of heavy chains onto $H A$. $|\alpha|$ is an unusual PG composed of the bikunin core protein to which a CS chain is attached (via a standard tetrasaccharide linker) and where 2 heavy chains ( $\mathrm{HC} 1$ and $\mathrm{HC} 2)$ are covalently linked to the CS via ester bonds (red circles); see references in [29]. P $\alpha$ l is a related PG that has a single HC (HC3) attached to the CS [157]. The HCs from l $\alpha$ l and Pal (HCs 1-3) are transferred onto HA (a GAG 
composed of a repeating disaccharide of glucuronic acid (diamonds) and $\mathrm{N}$-acteylglucosamine (squares)) in a process that is mediated by TSG-6 [27,29,95]. Here the HCs become linked via ester bonds to the HA chain to form covalent $\mathrm{HC} \cdot \mathrm{HA}$ complexes [97]. Two additional HCs (HC5 and HC6) are also likely to be transferred onto HA [96], however, it is not known whether they are linked to bikunin (although this seems probable for $\mathrm{HC}$ ) or another PG and, thus, what member of the I $\alpha$ l family they belong to (denoted by '?'s). It is, however, presumed that they are attached to a CS chain via an ester bond during biosynthesis, which is thought to be a prerequisite for transfer [95]. While there is evidence that $\mathrm{HC} \cdot \mathrm{HA}$ is formed (via the action of TSG-6) [96], there are no data for HC6. It should be noted that while all $5 \mathrm{HCs}$ are shown bound to a single HA chain, this is unlikely to happen in vivo, where $\mathrm{HC} \cdot \mathrm{HA}$ complexes with different compositions will be formed in different tissue contexts; see text for details.

Figure 5. Mechanism of TSG-6-mediated heavy chain transfer. A) The formation of $\mathrm{HC} \cdot \mathrm{HA}$ is a multistep process, where divalent cations $\left(\mathrm{M}^{2+}\right)$ are required at every stage $($ see $[29,95]$ and references therein); here this is illustrated for the transfer of $\mathrm{HC} 1$ and $\mathrm{HC} 2$ from lal onto $\mathrm{HA}$ since this is best understood. In the first step (a) a non-covalent complex forms stochastically between one of the HCs of $|\alpha|$ and the CUB module of TSG-6. This is dependent on a $\mathrm{Ca}^{2+}$ ion in TSG-6 (orange asterisk) and an $\mathrm{Mg}^{2+}$ or $\mathrm{Mn}^{2+}$ ion in the $\mathrm{HC}$ (yellow asterisk); in these lal/TSG-6 complexes the HCs are still attached by ester bonds (red circles) to the CS chain of bikunin. This process is fast and is mediated by a high-affinity, $\mathrm{M}^{2+}$-dependent, interaction. In step (b) these noncovalent I $\alpha$ I/TSG-6 complexes convert into covalent complexes where the C-terminal aspartic acid residue of the respective $\mathrm{HC}$ becomes linked by an ester bond to the $\mathrm{N}$-terminal peptide of TSG-6 [158]; i.e. to form HC1•TSG-6 or HC2•TSG-6 complexes and the HC2•CS•bikunin and $\mathrm{HC} 1 \cdot \mathrm{CS} \cdot$ bikunin by-products, respectively $[95,120]$. This is a slow (rate limiting) transesterification reaction that transfers the ester bond linking the HC to CS onto TSG-6, and (like step a) requires $\mathrm{Ca}^{2+}$ and $\mathrm{Mg}^{2+} / \mathrm{Mn}^{2+}$ ions [95]. The $\mathrm{HC} \cdot \mathrm{CS} \cdot$ bikunin by-products break down over time (dashed arrow) to release CS•bikunin [10]. The third step (c) transfers the HCs from the HC•TSG-6 complexes onto HA, where this also requires divalent cations [95], however, it is not known if both $\mathrm{Ca}^{2+}$ and/or $\mathrm{Mg}^{2+} / \mathrm{Mn}^{2+}$ are needed. This transfers the ester bond linking the respective HCs to 
TSG-6 onto the N-acetylglucosamine of HA. This second transesterification reaction releases TSG-6, which can then interact with a new l $\alpha$ l molecule; thus TSG-6 acts as the catalyst in this reaction [92]. B) A schematic (left) showing amino acids involved in steps a, b and $\mathbf{c}$ in (A). Glu183 (E183) forms part of the cation- binding site in the TSG-6 CUB module (middle) directly chelating the $\mathrm{Ca}^{2+}$ ion (orange asterisk); this bidentate amino acid also mediates the non-covalent interaction with $\mathrm{HCs}$ (step a), where it is likely that it interacts with the $\mathrm{Mg}^{2+} / \mathrm{Mn}^{2+}$ ion in the $\mathrm{HC}$ [29]. E183 is also required for the first transesterification reaction (step b), since mutation of this amino acid to serine in rhTSG-6 (E183S) drastically reduces the formation of the covalent HC.TSG-6 complexes, as shown in the SDS-PAGE gel (right). The ester bond formed involves Ser28 (S28) of TSG-6 [158]. The transfer of HCs onto HA (step c) requires the interaction of HA with the HC.TSG-6 complex, where Tyr47 (Y47), a residue involved in HA binding in free TSG-6, plays a role [29].

\section{Acknowledgements}

We would like to thank all of our friends and collaborators in the matrix biology field for making it such a great area to work in. We acknowledge Arthritis Research UK for funding our own research on TSG-6 for more than 25 years (current grants: 20895 and 21946) and everyone who has contributed to the understanding of this special protein. Special thanks go to David Briggs (Imperial College London, UK) for his help with Figure 1 and Ralf Richter (University of Leeds, UK) for many fruitful discussions. 


\section{References}

[1] T.H. Lee, H.G. Wisniewski, J. Vilcek, A novel secretory tumor necrosis factor-inducible protein (TSG-6) is a member of the family of hyaluronate binding proteins, closely related to the adhesion receptor CD44., J. Cell Biol. 116 (1992) 545-57. doi:10.1083/JCB.116.2.545.

[2] R.H. Lee, A.A. Pulin, M.J. Seo, D.J. Kota, J. Ylostalo, B.L. Larson, L. Semprun-Prieto, P. Delafontaine, D.J. Prockop, Intravenous hMSCs improve myocardial infarction in mice because cells embolized in lung are activated to secrete the anti-inflammatory protein TSG6., Cell Stem Cell. 5 (2009) 54-63. doi:10.1016/j.stem.2009.05.003.

[3] D.J. Prockop, Inflammation, fibrosis, and modulation of the process by mesenchymal stem/stromal cells, Matrix Biol. 51 (2016) 7-13. doi:10.1016/J.MATBIO.2016.01.010.

[4] C.M. Milner, A.J. Day, TSG-6: a multifunctional protein associated with inflammation., J. Cell Sci. 116 (2003) 1863-73. doi:10.1242/jcs.00407.

[5] C.M. Milner, V.A. Higman, A.J. Day, TSG-6: a pluripotent inflammatory mediator?, Biochem. Soc. Trans. 34 (2006) 446-50. doi:10.1042/BST0340446.

[6] C.M. Milner, W. Tongsoongnoen, M.S. Rugg, A.J. Day, The molecular basis of inter-alphainhibitor heavy chain transfer on to hyaluronan., Biochem. Soc. Trans. 35 (2007) 672-6. doi:10.1042/BST0350672.

[7] H.-G. Wisniewski, J. Vilček, Cytokine-induced gene expression at the crossroads of innate immunity, inflammation and fertility: TSG-6 and PTX3/TSG-14., Cytokine Growth Factor Rev. 15 (2004) 129-146. doi:10.1016/J.CYTOGFR.2004.01.005.

[8] S. Zhang, H. He, A.J. Day, S.C.G. Tseng, Constitutive expression of inter-a-inhibitor (lal) family proteins and tumor necrosis factor-stimulated gene-6 (TSG-6) by human amniotic membrane epithelial and stromal cells supporting formation of the heavy chain-hyaluronan (HC-HA) complex., J. Biol. Chem. 287 (2012) 12433-44. doi:10.1074/jbc.M112.342873.

[9] V.J. Coulson-Thomas, M.E. Lauer, S. Soleman, C. Zhao, V.C. Hascall, A.J. Day, J.W. Fawcett, Tumor Necrosis Factor-stimulated Gene-6 (TSG-6) is constitutively expressed in adult central nervous system (CNS) and associated with astrocyte-mediated glial scar formation following spinal cord injury., J. Biol. Chem. 291 (2016) 19939-19952. doi:10.1074/jbc.M115.710673. 
[10] R. Forteza, S.M. Casalino-Matsuda, M.E. Monzon, E. Fries, M.S. Rugg, C.M. Milner, A.J. Day, TSG-6 potentiates the antitissue kallikrein activity of inter-alpha-inhibitor through bikunin release., Am. J. Respir. Cell Mol. Biol. 36 (2007) 20-31. doi:10.1165/rcmb.200600180C.

[11] M. Kvezereli, S.A. Michie, T. Yu, R.J. Creusot, M.J. Fontaine, TSG-6 protein expression in the pancreatic islets of NOD mice., J. Mol. Histol. 39 (2008) 585-593. doi:10.1007/s10735008-9199-5.

[12] R.L. Hull, P.Y. Johnson, K.R. Braun, A.J. Day, T.N. Wight, Hyaluronan and hyaluronan binding proteins are normal components of mouse pancreatic islets and are differentially expressed by islet endocrine cell types., J. Histochem. Cytochem. 60 (2012) 749-60. doi:10.1369/0022155412457048.

[13] M. Bogdani, P.Y. Johnson, S. Potter-Perigo, N. Nagy, A.J. Day, P.L. Bollyky, T.N. Wight, Hyaluronan and hyaluronan-binding proteins accumulate in both human type 1 diabetic islets and lymphoid tissues and associate with inflammatory cells in insulitis., Diabetes. 63 (2014) 2727-43. doi:10.2337/db13-1658.

[14] N. Nagy, G. Kaber, P.Y. Johnson, J.A. Gebe, A. Preisinger, B.A. Falk, V.G. Sunkari, M.D. Gooden, R.B. Vernon, M. Bogdani, H.F. Kuipers, A.J. Day, D.J. Campbell, T.N. Wight, P.L. Bollyky, Inhibition of hyaluronan synthesis restores immune tolerance during autoimmune insulitis., J. Clin. Invest. 125 (2015) 3928-40. doi:10.1172/JCI79271.

[15] K. Tan, D. McGrouther, A. Day, C. Milner, A. Bayat, Characterization of hyaluronan and TSG-6 in skin scarring: differential distribution in keloid scars, normal scars and unscarred skin., J. Eur. Acad. Dermatology Venereol. 25 (2011) 317-327. doi:10.1111/j.14683083.2010.03792.x.

[16] H. He, W. Li, D.Y. Tseng, S. Zhang, S.-Y. Chen, A.J. Day, S.C.G. Tseng, Biochemical characterization and function of complexes formed by hyaluronan and the heavy chains of inter-alpha-inhibitor $(\mathrm{HC} \cdot \mathrm{HA})$ purified from extracts of human amniotic membrane., J. Biol. Chem. 284 (2009) 20136-46. doi:10.1074/jbc.M109.021881.

[17] F.S. Magaña-Guerrero, A. Domínguez-López, P. Martínez-Aboytes, B. Buentello-Volante, Y. Garfias, Human amniotic membrane mesenchymal stem cells inhibit neutrophil extracellular 
traps through TSG-6., Sci. Rep. 7 (2017) 12426. doi:10.1038/s41598-017-10962-2.

[18] S.C.G. Tseng, HC-HA/PTX3 purified from amniotic membrane as novel regenerative Matrix: insight into relationship between inflammation and regeneration., Investig. Opthalmology Vis. Sci. 57 (2016) ORSFh1. doi:10.1167/iovs.15-17637.

[19] V.P. Stober, C.G. Johnson, A. Majors, M.E. Lauer, V. Cali, R.J. Midura, H.-G. Wisniewski, M.A. Aronica, S. Garantziotis, TNF-stimulated gene 6 promotes formation of hyaluronaninter-a-inhibitor heavy chain complexes necessary for ozone-induced airway hyperresponsiveness., J. Biol. Chem. (2017) jbc.M116.756627. doi:10.1074/jbc.M116.756627.

[20] S. Danchuk, J.H. Ylostalo, F. Hossain, R. Sorge, A. Ramsey, R.W. Bonvillain, J.A. Lasky, B.A. Bunnell, D.A. Welsh, D.J. Prockop, D.E. Sullivan, Human multipotent stromal cells attenuate lipopolysaccharide-induced acute lung injury in mice via secretion of tumor necrosis factor- $\alpha$-induced protein 6., Stem Cell Res. Ther. 2 (2011) 27. doi:10.1186/scrt68.

[21] A.M. Foskett, N. Bazhanov, X. Ti, A. Tiblow, T.J. Bartosh, D.J. Prockop, Phase-directed therapy: TSG-6 targeted to early inflammation improves bleomycin-injured lungs., Am. J. Physiol. Lung Cell. Mol. Physiol. 306 (2014) L120-31. doi:10.1152/ajplung.00240.2013.

[22] M. Mittal, C. Tiruppathi, S. Nepal, Y.-Y. Zhao, D. Grzych, D. Soni, D.J. Prockop, A.B. Malik, TNFa-stimulated gene-6 (TSG6) activates macrophage phenotype transition to prevent inflammatory lung injury., Proc. Natl. Acad. Sci. U. S. A. 113 (2016) E8151-E8158. doi:10.1073/pnas.1614935113.

[23] R.M.L. Simpson, S. Meran, D. Thomas, P. Stephens, T. Bowen, R. Steadman, A. Phillips, Age-Related Changes in Pericellular Hyaluronan Organization Leads to Impaired Dermal Fibroblast to Myofibroblast Differentiation., Am. J. Pathol. 175 (2009) 1915-1928. doi:10.2353/AJPATH.2009.090045.

[24] V. Maina, A. Cotena, A. Doni, M. Nebuloni, F. Pasqualini, C.M. Milner, A.J. Day, A. Mantovani, C. Garlanda, Coregulation in human leukocytes of the long pentraxin PTX3 and TSG-6., J. Leukoc. Biol. 86 (2009) 123-132. doi:10.1189/jlb.0608345.

[25] G. Nagyeri, M. Radacs, S. Ghassemi-Nejad, B. Tryniszewska, K. Olasz, G. Hutas, Z. Gyorfy, V.C. Hascall, T.T. Glant, K. Mikecz, TSG-6 protein, a negative regulator of 
inflammatory arthritis, forms a ternary complex with murine mast cell tryptases and heparin., J. Biol. Chem. 286 (2011) 23559-69. doi:10.1074/jbc.M111.222026.

[26] D. Mukhopadhyay, V.C. Hascall, A.J. Day, A. Salustri, C. Fülöp, Two distinct populations of Tumor Necrosis Factor-Stimulated Gene-6 protein in the extracellular matrix of expanded mouse cumulus cell-oocyte complexes., Arch. Biochem. Biophys. 394 (2001) 173-181. doi:10.1006/ABBI.2001.2552.

[27] C. Fülöp, S. Szántó, D. Mukhopadhyay, T. Bárdos, R. V Kamath, M.S. Rugg, A.J. Day, A. Salustri, V.C. Hascall, T.T. Glant, K. Mikecz, Impaired cumulus mucification and female sterility in tumor necrosis factor-induced protein-6 deficient mice., Development. 130 (2003) 2253-61. doi:10.1242/DEV.00422.

[28] S.A. Ochsner, A.J. Day, M.S. Rugg, R.M. Breyer, R.H. Gomer, J.S. Richards, Disrupted function of tumor necrosis factor-alpha-stimulated gene 6 blocks cumulus cell-oocyte complex expansion., Endocrinology. 144 (2003) 4376-84. doi:10.1210/en.2003-0487.

[29] D.C. Briggs, H.L. Birchenough, T. Ali, M.S. Rugg, J.P. Waltho, E. levoli, T.A. Jowitt, J.J. Enghild, R.P. Richter, A. Salustri, C.M. Milner, A.J. Day, Metal lon-dependent heavy chain transfer activity of TSG-6 mediates assembly of the cumulus-oocyte matrix., J. Biol. Chem. 290 (2015) 28708-23. doi:10.1074/jbc.M115.669838.

[30] S.A. Ochsner, D.L. Russell, A.J. Day, R.M. Breyer, J.S. Richards, Decreased expression of tumor necrosis factor-alpha-stimulated gene 6 in cumulus cells of the cyclooxygenase-2 and EP2 null mice., Endocrinology. 144 (2003) 1008-19. doi:10.1210/en.2002-220435.

[31] N.M. Hohos, K.J. Cho, D.C. Swindle, M.E. Skaznik-Wikiel, High-fat diet exposure, regardless of induction of obesity, is associated with altered expression of genes critical to normal ovulatory function., Mol. Cell. Endocrinol. (2017). doi:10.1016/J.MCE.2017.10.016.

[32] K. Sayasith, M. Doré, J. Sirois, Molecular characterization of tumor necrosis alpha-induced protein 6 and its human chorionic gonadotropin-dependent induction in theca and mural granulosa cells of equine preovulatory follicles., Reproduction. 133 (2007) 135-45. doi:10.1530/rep.1.01200.

[33] E. Nagyova, A. Camaioni, R. Prochazka, A.J. Day, A. Salustri, Synthesis of tumor necrosis factor alpha-induced protein 6 in porcine preovulatory follicles: a study with A38 antibody., 
Biol. Reprod. 78 (2008) 903-9. doi:10.1095/biolreprod.107.064832.

[34] E.S. Caixeta, M.L. Sutton-McDowall, R.B. Gilchrist, J.G. Thompson, C.A. Price, M.F. Machado, P.F. Lima, J. Buratini, Bone morphogenetic protein 15 and fibroblast growth factor 10 enhance cumulus expansion, glucose uptake, and expression of genes in the ovulatory cascade during in vitro maturation of bovine cumulus-oocyte complexes., Reproduction. 146 (2013) 27-35. doi:10.1530/REP-13-0079.

[35] R.-N. Zhang, B. Pang, S.-R. Xu, P.-C. Wan, S.-C. Guo, H.-Z. Ji, G.-X. Jia, L.-Y. Hu, X.-Q. Zhao, Q.-E. Yang, The CXCL12-CXCR4 signaling promotes oocyte maturation by regulating cumulus expansion in sheep., Theriogenology. $107 \quad$ (2018) 85-94. doi:10.1016/J.THERIOGENOLOGY.2017.10.039.

[36] T.J. Bartosh, J.H. Ylöstalo, A. Mohammadipoor, N. Bazhanov, K. Coble, K. Claypool, R.H. Lee, H. Choi, D.J. Prockop, Aggregation of human mesenchymal stromal cells (MSCs) into 3D spheroids enhances their antiinflammatory properties., Proc. Natl. Acad. Sci. U. S. A. 107 (2010) 13724-9. doi:10.1073/pnas.1008117107.

[37] T. Kato, M. Okumi, M. Tanemura, K. Yazawa, Y. Kakuta, K. Yamanaka, K. Tsutahara, Y. Doki, M. Mori, S. Takahara, N. Nonomura, Adipose tissue-derived stem cells suppress acute cellular rejection by TSG-6 and CD44 interaction in rat kidney transplantation., Transplantation. 98 (2014) 277-84. doi:10.1097/TP.0000000000000230.

[38] J. Xie, H.E. Broxmeyer, D. Feng, K.S. Schweitzer, R. Yi, T.G. Cook, B.R. Chitteti, D. Barwinska, D.O. Traktuev, M.J. Van Demark, M.J. Justice, X. Ou, E.F. Srour, D.J. Prockop, I. Petrache, K.L. March, Human adipose-derived stem cells ameliorate cigarette smokeinduced murine myelosuppression via secretion of TSG-6., Stem Cells. 33 (2015) 468-78. doi:10.1002/stem.1851.

[39] W.-J. Song, Q. Li, M.-O. Ryu, J.-O. Ahn, D. Ha Bhang, Y. Chan Jung, H.-Y. Youn, TSG-6 secreted by human adipose tissue-derived mesenchymal stem cells ameliorates DSSinduced colitis by inducing M2 macrophage polarization in mice., Sci. Rep. 7 (2017) 5187. doi:10.1038/s41598-017-04766-7.

[40] T. Maruyama, N. Fukuda, T. Matsumoto, K. Kano, M. Endo, M. Kazama, T. Kazama, J. Ikeda, H. Matsuda, T. Ueno, M. Abe, K. Okada, M. Soma, K. Matsumoto, H. Kawachi, 
Systematic implantation of dedifferentiated fat cells ameliorated monoclonal antibody 1-223-induced glomerulonephritis by immunosuppression with increases in TNF-stimulated gene 6., Stem Cell Res. Ther. 6 (2015) 80. doi:10.1186/s13287-015-0069-2.

[41] V.J. Coulson-Thomas, T.F. Gesteira, V. Hascall, W. Kao, Umbilical cord mesenchymal stem cells suppress host rejection: the role of the glycocalyx., J. Biol. Chem. 289 (2014) 2346581. doi:10.1074/jbc.M114.557447.

[42] L. Liu, H. Song, H. Duan, J. Chai, J. Yang, X. Li, Y. Yu, X. Zhang, X. Hu, M. Xiao, R. Feng, H. Yin, Q. Hu, L. Yang, J. Du, T. Li, TSG-6 secreted by human umbilical cord-MSCs attenuates severe burn-induced excessive inflammation via inhibiting activations of P38 and JNK signaling., Sci. Rep. 6 (2016) 30121. doi:10.1038/srep30121.

[43] S. Hamidian Jahromi, Y. Li, J.E. Davies, Effect of Tumor Necrosis Factor Alpha Dose and Exposure Time on Tumor Necrosis Factor Induced Gene-6 Activation by Neonatal and Adult Mesenchymal Stromal Cells., Stem Cells Dev. (2017) scd.2017.0179. doi:10.1089/scd.2017.0179.

[44] M.Y. Chang, C.K. Chan, K.R. Braun, P.S. Green, K.D. O’Brien, A. Chait, A.J. Day, T.N. Wight, Monocyte-to-macrophage differentiation: synthesis and secretion of a complex extracellular matrix., J. Biol. Chem. 287 (2012) 14122-35. doi:10.1074/jbc.M111.324988.

[45] D.J. Mahoney, C. Swales, N.A. Athanasou, M. Bombardieri, C. Pitzalis, K. Kliskey, M. Sharif, A.J. Day, C.M. Milner, A. Sabokbar, TSG-6 inhibits osteoclast activity via an autocrine mechanism and is functionally synergistic with osteoprotegerin., Arthritis Rheum. 63 (2011) 1034-43. doi:10.1002/art.30201.

[46] S.K. Wang, J. Xie, L.A. Green, R.A. McCready, R.L. Motaganahalli, A. Fajardo, C.C. Babbey, M.P. Murphy, TSG-6 is highly expressed in human abdominal aortic aneurysms., J. Surg. Res. 220 (2017) 311-319. doi:10.1016/J.JSS.2017.06.078.

[47] E. Capp, C.M. Milner, J. Williams, L. Hauck, J. Jauckus, T. Strowitzki, A. Germeyer, Modulation of tumor necrosis factor-stimulated gene-6 (TSG-6) expression in human endometrium., Arch. Gynecol. Obstet. 289 (2014) 893-901. doi:10.1007/s00404-013-30809.

[48] M. Matteo, E. Cicinelli, M. Neri, R. Carrubba, F.A. Carpagnano, F. Romeo, G. Scutiero, P. 
Greco, C. Garlanda, G. Vendemiale, P.E. Levi Setti, G. Serviddio, Pro-inflammatory M1/Th1 type immune network and increased expression of TSG-6 in the eutopic endometrium from women with endometriosis., Eur. J. Obstet. Gynecol. Reprod. Biol. 218 (2017) 99-105. doi:10.1016/J.EJOGRB.2017.08.014.

[49] H.-G. Wisniewski, E. Colón, V. Liublinska, R.J. Karia, T.V. Stabler, M. Attur, S.B. Abramson, P.A. Band, V.B. Kraus, TSG-6 activity as a novel biomarker of progression in $\begin{array}{lllll}\text { knee osteoarthritis., } & \text { Osteoarthr. } & \text { Cartil. } & 22 & \text { (2014) 235-241. }\end{array}$ doi:10.1016/J.JOCA.2013.12.004.

[50] S. Snelling, R. Rout, R. Davidson, I. Clark, A. Carr, P.A. Hulley, A.J. Price, A gene expression study of normal and damaged cartilage in anteromedial gonarthrosis, a phenotype of osteoarthritis., Osteoarthr. Cartil. 22 (2014) 334-343. doi:10.1016/J.JOCA.2013.12.009.

[51] C.-H. Chou, M.T.M. Lee, I.-W. Song, L.-S. Lu, H.-C. Shen, C.-H. Lee, J.-Y. Wu, Y.-T. Chen, V.B. Kraus, C.-C. Wu, Insights into osteoarthritis progression revealed by analyses of both knee tibiofemoral compartments., Osteoarthr. Cartil. $23 \quad$ (2015) 571-580. doi:10.1016/J.JOCA.2014.12.020.

[52] S.L. Dunn, J. Soul, S. Anand, J.-M. Schwartz, R.P. Boot-Handford, T.E. Hardingham, Gene expression changes in damaged osteoarthritic cartilage identify a signature of nonchondrogenic and mechanical responses., Osteoarthr. Cartil. 24 (2016) 1431-1440. doi:10.1016/J.JOCA.2016.03.007.

[53] C.-H. Chou, D.E. Attarian, H.-G. Wisniewski, P.A. Band, V.B. Kraus, TSG-6 - a doubleedged sword for osteoarthritis (OA)., Osteoarthr. Cartil. (2017). doi:10.1016/J.JOCA.2017.10.019.

[54] A. Burleigh, A. Chanalaris, M.D. Gardiner, C. Driscoll, O. Boruc, J. Saklatvala, T.L. Vincent, Joint immobilization prevents murine osteoarthritis and reveals the highly mechanosensitive nature of protease expression in vivo., Arthritis Rheum. 64 (2012) 2278-2288. doi:10.1002/art.34420.

[55] F.E. Watt, E. Paterson, A. Freidin, M. Kenny, A. Judge, J. Saklatvala, A. Williams, T.L. Vincent, Acute molecular changes in synovial fluid following human knee injury: association 
with early clinical outcomes., Arthritis Rheumatol. (Hoboken, N.J.). 68 (2016) 2129-40. doi:10.1002/art.39677.

[56] S. Szántó, T. Bárdos, I. Gál, T.T. Glant, K. Mikecz, Enhanced neutrophil extravasation and rapid progression of proteoglycan-induced arthritis in TSG-6-knockout mice, Arthritis Rheum. 50 (2004) 3012-3022. doi:10.1002/art.20655.

[57] D. Kohda, C.J. Morton, A.A. Parkar, H. Hatanaka, F.M. Inagaki, I.D. Campbell, A.J. Day, Solution structure of the Link module: A hyaluronan-binding domain involved in extracellular matrix stability and cell migration., Cell. 86 (1996) 767-775. doi:10.1016/S00928674(00)80151-8.

[58] C.D. Blundell, D.J. Mahoney, A. Almond, P.L. DeAngelis, J.D. Kahmann, P. Teriete, A.R. Pickford, I.D. Campbell, A.J. Day, The link module from ovulation- and inflammationassociated protein TSG-6 changes conformation on hyaluronan binding., J. Biol. Chem. 278 (2003) 49261-70. doi:10.1074/jbc.M309623200.

[59] V.A. Higman, C.D. Blundell, D.J. Mahoney, C. Redfield, M.E.M. Noble, A.J. Day, Plasticity of the TSG-6 HA-binding loop and mobility in the TSG-6-HA complex revealed by NMR and Xray crystallography., J. Mol. Biol. 371 (2007) 669-84. doi:10.1016/j.jmb.2007.05.073.

[60] C.D. Blundell, A. Almond, D.J. Mahoney, P.L. DeAngelis, I.D. Campbell, A.J. Day, Towards a structure for a TSG-6.hyaluronan complex by modeling and NMR spectroscopy: insights into other members of the link module superfamily., J. Biol. Chem. 280 (2005) 18189-201. doi:10.1074/jbc.M414343200.

[61] V.A. Higman, D.C. Briggs, D.J. Mahoney, C.D. Blundell, B.M. Sattelle, D.P. Dyer, D.E. Green, P.L. DeAngelis, A. Almond, C.M. Milner, A.J. Day, A refined model for the TSG-6 link module in complex with hyaluronan: use of defined oligosaccharides to probe structure and function., J. Biol. Chem. 289 (2014) 5619-34. doi:10.1074/jbc.M113.542357.

[62] N.S. Baranova, E. Nilebäck, F.M. Haller, D.C. Briggs, S. Svedhem, A.J. Day, R.P. Richter, The inflammation-associated protein TSG-6 cross-links hyaluronan via hyaluronan-induced TSG-6 oligomers., J. Biol. Chem. 286 (2011) 25675-86. doi:10.1074/jbc.M111.247395.

[63] S. Banerji, A.J. Wright, M. Noble, D.J. Mahoney, I.D. Campbell, A.J. Day, D.G. Jackson, Structures of the Cd44-hyaluronan complex provide insight into a fundamental 
carbohydrate-protein interaction., Nat. Struct. Mol. Biol. 14 (2007) 234-9. doi:10.1038/nsmb1201.

[64] R.P. Richter, N.S. Baranova, A.J. Day, J.C. Kwok, Glycosaminoglycans in extracellular matrix organisation: are concepts from soft matter physics key to understanding the formation of perineuronal nets?, Curr. Opin. Struct. Biol. 50 (2018) 65-74. doi:10.1016/j.sbi.2017.12.002.

[65] Y. Park, T.A. Jowitt, A.J. Day, J.H. Prestegard, Nuclear Magnetic Resonance insight into the multiple glycosaminoglycan binding modes of the Link module from human TSG-6., Biochemistry. 55 (2016) 262-76. doi:10.1021/acs.biochem.5b01148.

[66] A.A. Parkar, A.J. Day, Overlapping sites on the Link module of human TSG-6 mediate binding to hyaluronan and chondroitin-4-sulphate, FEBS Lett. 410 (1997) 413-417. doi:10.1016/S0014-5793(97)00621-2.

[67] B.C. Heng, P.M. Gribbon, A.J. Day, T.E. Hardingham, Hyaluronan binding to link module of TSG-6 and to G1 domain of aggrecan is differently regulated by pH., J. Biol. Chem. 283 (2008) 32294-301. doi:10.1074/jbc.M804155200.

[68] A. Marson, D.E. Robinson, P.N. Brookes, B. Mulloy, M. Wiles, S.J. Clark, H.L. Fielder, L.J. Collinson, S.A. Cain, C.M. Kielty, S. McArthur, D.J. Buttle, R.D. Short, J.D. Whittle, A.J. Day, Development of a microtiter plate-based glycosaminoglycan array for the investigation of glycosaminoglycan-protein interactions, Glycobiology. $19 \quad(2009) \quad 1537-1546$. doi:10.1093/glycob/cwp132.

[69] D.J. Mahoney, B. Mulloy, M.J. Forster, C.D. Blundell, E. Fries, C.M. Milner, A.J. Day, Characterization of the interaction between tumor necrosis factor-stimulated gene-6 and heparin: implications for the inhibition of plasmin in extracellular matrix microenvironments., J. Biol. Chem. 280 (2005) 27044-55. doi:10.1074/jbc.M502068200.

[70] T.N. Wight, Provisional matrix: A role for versican and hyaluronan., Matrix Biol. 60-61 (2017) 38-56. doi:10.1016/J.MATBIO.2016.12.001.

[71] N.S. Baranova, S.J. Foulcer, D.C. Briggs, V. Tilakaratna, J.J. Enghild, C.M. Milner, A.J. Day, R.P. Richter, Inter-a-inhibitor impairs TSG-6-induced hyaluronan cross-linking., J. Biol. Chem. 288 (2013) 29642-53. doi:10.1074/jbc.M113.477422. 
[72] N.S. Baranova, A. Inforzato, D.C. Briggs, V. Tilakaratna, J.J. Enghild, D. Thakar, C.M. Milner, A.J. Day, R.P. Richter, Incorporation of pentraxin 3 into hyaluronan matrices Is tightly regulated and promotes matrix cross-linking., J. Biol. Chem. 289 (2014) 30481-30498. doi:10.1074/jbc.M114.568154.

[73] J.D. Humphrey, E.R. Dufresne, M.A. Schwartz, Mechanotransduction and extracellular matrix homeostasis., Nat. Rev. Mol. Cell Biol. 15 (2014) 802-12. doi:10.1038/nrm3896.

[74] J. Lesley, I. Gál, D.J. Mahoney, M.R. Cordell, M.S. Rugg, R. Hyman, A.J. Day, K. Mikecz, TSG-6 modulates the interaction between hyaluronan and cell surface CD44., J. Biol. Chem. 279 (2004) 25745-54. doi:10.1074/jbc.M313319200.

[75] W. Lawrance, S. Banerji, A.J. Day, S. Bhattacharjee, D.G. Jackson, Binding of hyaluronan to the native Lymphatic Vessel Endothelial Receptor LYVE-1 Is critically dependent on receptor clustering and hyaluronan organization., J. Biol. Chem. 291 (2016) 8014-30. doi:10.1074/jbc.M115.708305.

[76] S. Banerji, W. Lawrance, C. Metcalfe, D.C. Briggs, A. Yamauchi, O. Dushek, P.A. van der Merwe, A.J. Day, D.G. Jackson, Homodimerization of the Lymph Vessel Endothelial Receptor LYVE-1 through a redox-labile disulfide is critical for hyaluronan binding in lymphatic endothelium., J. Biol. Chem. $291 \quad$ (2016) 25004-25018. doi:10.1074/jbc.M116.736926.

[77] Y. Kim, G.A. West, G. Ray, S.P. Kessler, A.C. Petrey, C. Fiocchi, C. McDonald, M.S. Longworth, L.E. Nagy, C.A. de la Motte, Layilin is critical for mediating hyaluronan 35 kDainduced intestinal epithelial tight junction protein ZO-1 in vitro and in vivo., Matrix Biol. (2017). doi:10.1016/J.MATBIO.2017.09.003.

[78] H. Choi, R.H. Lee, N. Bazhanov, J.Y. Oh, D.J. Prockop, Anti-inflammatory protein TSG-6 secreted by activated MSCs attenuates zymosan-induced mouse peritonitis by decreasing TLR2/NF-KB signaling in resident macrophages., Blood. 118 (2011) 330-8. doi:10.1182/blood-2010-12-327353.

[79] D.J. Kota, L.L. Wiggins, N. Yoon, R.H. Lee, TSG-6 produced by hMSCs delays the onset of autoimmune diabetes by suppressing Th1 development and enhancing tolerogenicity., Diabetes. 62 (2013) 2048-58. doi:10.2337/db12-0931. 
[80] A. Almond, C.D. Blundell, V.A. Higman, A.D. MacKerell,, A.J. Day, Using molecular dynamics simulations to provide new insights into protein structure on the nanosecond timescale: comparison with experimental data and biological inferences for the hyaluronanbinding Link module of TSG-6., J. Chem. Theory Comput. 3 (2007) 1-16. doi:10.1021/ct600236q.

[81] H. Birchenough, Investigation of the tumour necrosis factor-stimulated gene-6 (TSG-6) interactome; use and development of surface sensitive techniques., [Thesis]. Univ. Manchester UK; 2014. (2014). https://www.escholar.manchester.ac.uk/uk-ac-manscw:239838.

[82] D.P. Dyer, C.L. Salanga, S.C. Johns, E. Valdambrini, M.M. Fuster, C.M. Milner, A.J. Day, T.M. Handel, The Anti-inflammatory Protein TSG-6 Regulates Chemokine Function by Inhibiting Chemokine/Glycosaminoglycan Interactions., J. Biol. Chem. 291 (2016) 1262740. doi:10.1074/jbc.M116.720953.

[83] H.G. Wisniewski, J.C. Hua, D.M. Poppers, D. Naime, J. Vilcek, B.N. Cronstein, TNF/IL-1inducible protein TSG-6 potentiates plasmin inhibition by inter-alpha-inhibitor and exerts a strong anti-inflammatory effect in vivo., J. Immunol. 156 (1996) 1609-15. http://www.ncbi.nlm.nih.gov/pubmed/8568267 (accessed December 8, 2017).

[84] S.J. Getting, D.J. Mahoney, T. Cao, M.S. Rugg, E. Fries, C.M. Milner, M. Perretti, A.J. Day, The link module from human TSG-6 inhibits neutrophil migration in a hyaluronan- and interalpha-inhibitor-independent manner., J. Biol. Chem. 277 (2002) 51068-76. doi:10.1074/jbc.M205121200.

[85] K.W. Sanggaard, C.S. Sonne-Schmidt, C. Jacobsen, I.B. Thøgersen, Z. Valnickova, H.-G. Wisniewski, J.J. Enghild, Evidence for a two-step mechanism involved in the formation of covalent HC·TSG-6 complexes., Biochemistry. 45 (2006) 7661-8. doi:10.1021/BI060106S.

[86] A.A. Parkar, J.D. Kahmann, S.L.. Howat, M.T. Bayliss, A.J. Day, TSG-6 interacts with hyaluronan and aggrecan in a $\mathrm{pH}-d e p e n d e n t$ manner via a common functional element: implications for its regulation in inflamed cartilage, FEBS Lett. 428 (1998) 171-176. doi:10.1016/S0014-5793(98)00523-7.

[87] M.T. Bayliss, S.L.T. Howat, J. Dudhia, J.M. Murphy, F.P. Barry, J.C.W. Edwards, A.J. Day, 
Up-regulation and differential expression of the hyaluronan-binding protein TSG-6 in cartilage and synovium in rheumatoid arthritis and osteoarthritis., Osteoarthr. Cartil. 9 (2001) 42-48. doi:10.1053/JOCA.2000.0348.

[88] C.D. Blundell, D.J. Mahoney, M.R. Cordell, A. Almond, J.D. Kahmann, A. Perczel, J.D. Taylor, I.D. Campbell, A.J. Day, Determining the molecular basis for the $\mathrm{pH}$-dependent interaction between the link module of human TSG-6 and hyaluronan., J. Biol. Chem. 282 (2007) 12976-88. doi:10.1074/jbc.M611713200.

[89] Y. Yoshihara, A. Plaas, B. Osborn, A. Margulis, F. Nelson, M. Stewart, M.S. Rugg, C.M. Milner, A.J. Day, K. Nemoto, J.D. Sandy, Superficial zone chondrocytes in normal and osteoarthritic human articular cartilages synthesize novel truncated forms of inter-alphatrypsin inhibitor heavy chains which are attached to a chondroitin sulfate proteoglycan other than bikunin., Osteoarthr. Cartil. 16 (2008) 1343-1355. doi:10.1016/J.JOCA.2008.04.004.

[90] D. Mukhopadhyay, A. Asari, M.S. Rugg, A.J. Day, C. Fülöp, Specificity of the tumor necrosis factor-induced protein 6-mediated heavy chain transfer from inter-alpha-trypsin inhibitor to hyaluronan: implications for the assembly of the cumulus extracellular matrix., J. Biol. Chem. 279 (2004) 11119-28. doi:10.1074/jbc.M313471200.

[91] M.E. Lauer, V.C. Hascall, D.E. Green, P.L. DeAngelis, A. Calabro, Irreversible heavy chain transfer to chondroitin., J. Biol. Chem. 289 (2014) 29171-9. doi:10.1074/jbc.M114.600809.

[92] G. V Eriksen, I. Carlstedt, M. Mörgelin, N. Uldbjerg, A. Malmström, Isolation and characterization of proteoglycans from human follicular fluid., Biochem. J. 340 ( Pt 3) (1999) 613-20. doi:10.1042/BJ3400613.

[93] E. Lamkin, G. Cheng, A. Calabro, V.C. Hascall, E.J. Joo, L. Li, R.J. Linhardt, M.E. Lauer, Heavy chain transfer by tumor necrosis factor-stimulated gene 6 to the bikunin proteoglycan., J. Biol. Chem. 290 (2015) 5156-66. doi:10.1074/jbc.M114.636258.

[94] K.W. Sanggaard, L. Hansen, C. Scavenius, H.-G. Wisniewski, T. Kristensen, I.B. Thøgersen, J.J. Enghild, Evolutionary conservation of heavy chain protein transfer between glycosaminoglycans., Biochim. Biophys. Acta - Proteins Proteomics. 1804 (2010) 10111019. doi:10.1016/J.BBAPAP.2010.01.013.

[95] M.S. Rugg, A.C. Willis, D. Mukhopadhyay, V.C. Hascall, E. Fries, C. Fülöp, C.M. Milner, A.J. 
Day, Characterization of complexes formed between TSG-6 and inter-alpha-inhibitor that act as intermediates in the covalent transfer of heavy chains onto hyaluronan., J. Biol. Chem. 280 (2005) 25674-86. doi:10.1074/jbc.M501332200.

[96] J. Martin, A. Midgley, S. Meran, E. Woods, T. Bowen, A.O. Phillips, R. Steadman, Tumor Necrosis Factor-stimulated gene 6 (TSG-6)-mediated interactions with the inter-a-inhibitor Heavy Chain 5 Facilitate Tumor Growth Factor $\beta 1$ (TGF $\beta 1$ )-dependent fibroblast to myofibroblast differentiation., J. Biol. Chem. $291 \quad$ (2016) 13789-801. doi:10.1074/jbc.M115.670521.

[97] M. Zhao, M. Yoneda, Y. Ohashi, S. Kurono, H. Iwata, Y. Ohnuki, K. Kimata, Evidence for the covalent binding of SHAP, heavy chains of inter-alpha-trypsin inhibitor, to hyaluronan., J. Biol. Chem. 270 (1995) 26657-63. doi:10.1074/JBC.270.44.26657.

[98] D. Kida, M. Yoneda, S. Miyaura, T. Ishimaru, Y. Yoshida, T. Ito, N. Ishiguro, H. Iwata, K. Kimata, The SHAP-HA complex in sera from patients with rheumatoid arthritis and $\begin{array}{lllll}\text { osteoarthritis., } & \text { J. } & \text { Rheumatol. } & 26 & \text { (1999) }\end{array}$ http://www.ncbi.nlm.nih.gov/pubmed/10381035 (accessed December 11, 2017).

[99] W. Yingsung, L. Zhuo, M. Morgelin, M. Yoneda, D. Kida, H. Watanabe, N. Ishiguro, H. Iwata, K. Kimata, Molecular heterogeneity of the SHAP-hyaluronan complex. Isolation and characterization of the complex in synovial fluid from patients with rheumatoid arthritis., J. Biol. Chem. 278 (2003) 32710-8. doi:10.1074/jbc.M303658200.

[100] A. Inforzato, V. Rivieccio, A.P. Morreale, A. Bastone, A. Salustri, L. Scarchilli, A. Verdoliva, S. Vincenti, G. Gallo, C. Chiapparino, L. Pacello, E. Nucera, O. Serlupi-Crescenzi, A.J. Day, B. Bottazzi, A. Mantovani, R. De Santis, G. Salvatori, Structural characterization of PTX3 disulfide bond network and its multimeric status in cumulus matrix organization., J. Biol. Chem. 283 (2008) 10147-61. doi:10.1074/jbc.M708535200.

[101] A. Inforzato, C. Baldock, T.A. Jowitt, D.F. Holmes, R. Lindstedt, M. Marcellini, V. Rivieccio, D.C. Briggs, K.E. Kadler, A. Verdoliva, B. Bottazzi, A. Mantovani, G. Salvatori, A.J. Day, The angiogenic inhibitor long pentraxin PTX3 forms an asymmetric octamer with two binding sites for FGF2., J. Biol. Chem. 285 (2010) 17681-92. doi:10.1074/jbc.M109.085639.

[102] A. Salustri, C. Garlanda, E. Hirsch, M. De Acetis, A. Maccagno, B. Bottazzi, A. Doni, A. 
Bastone, G. Mantovani, P. Beck Peccoz, G. Salvatori, D.J. Mahoney, A.J. Day, G. Siracusa, L. Romani, A. Mantovani, PTX3 plays a key role in the organization of the cumulus oophorus extracellular matrix and in in vivo fertilization., Development. 131 (2004) 1577-86. doi:10.1242/dev.01056.

[103] E. levoli, R. Lindstedt, A. Inforzato, A. Camaioni, F. Palone, A.J. Day, A. Mantovani, G. Salvatori, A. Salustri, Implication of the oligomeric state of the N-terminal PTX3 domain in cumulus matrix assembly., Matrix Biol. $30 \quad$ (2011) 330-337. doi:10.1016/j.matbio.2011.05.002.

[104] A.J. Day, C.A. de la Motte, Hyaluronan cross-linking: a protective mechanism in inflammation?, Trends Immunol. 26 (2005) 637-43. doi:10.1016/j.it.2005.09.009.

[105] L. Zhuo, A. Kanamori, R. Kannagi, N. Itano, J. Wu, M. Hamaguchi, N. Ishiguro, K. Kimata, SHAP potentiates the CD44-mediated leukocyte adhesion to the hyaluronan substratum., J. Biol. Chem. 281 (2006) 20303-14. doi:10.1074/jbc.M506703200.

[106] E. Shay, H. He, S. Sakurai, S.C.G. Tseng, Inhibition of angiogenesis by HC•HA, a complex of hyaluronan and the heavy chain of inter-a-inhibitor, purified from human amniotic membrane., Investig. Opthalmology Vis. Sci. 52 (2011) 2669. doi:10.1167/iovs.10-5888.

[107] H. He, S. Zhang, S. Tighe, J. Son, S.C.G. Tseng, Immobilized heavy chain-hyaluronic acid polarizes lipopolysaccharide-activated macrophages toward M2 phenotype., J. Biol. Chem. 288 (2013) 25792-803. doi:10.1074/jbc.M113.479584.

[108] Y. Ogawa, H. He, S. Mukai, T. Imada, S. Nakamura, C.-W. Su, M. Mahabole, S.C.G. Tseng, K. Tsubota, Heavy chain-hyaluronan/pentraxin 3 from amniotic membrane suppresses inflammation and scarring in murine lacrimal gland and conjunctiva of chronic graft-versushost disease., Sci. Rep. 7 (2017) 42195. doi:10.1038/srep42195.

[109] S. Zhang, Y.-T. Zhu, S.-Y. Chen, H. He, S.C.G. Tseng, Constitutive expression of pentraxin 3 (PTX3) protein by human amniotic membrane cells leads to formation of the heavy chain (HC)-hyaluronan (HA)-PTX3 complex., J. Biol. Chem. 289 (2014) 13531-42. doi:10.1074/jbc.M113.525287.

[110] A. Abbadi, M. Lauer, S. Swaidani, A. Wang, V. Hascall, Hyaluronan Rafts on Airway Epithelial Cells., J. Biol. Chem. 291 (2016) 1448-55. doi:10.1074/jbc.M115.704288. 
[111] B. Matuska, S. Comhair, C. Farver, J. Chmiel, R.J. Midura, T. Bonfield, M.E. Lauer, Pathological hyaluronan matrices in cystic fibrosis airways and secretions., Am. J. Respir. Cell Mol. Biol. 55 (2016) 576-585. doi:10.1165/rcmb.2015-03580C.

[112] S. Swaidani, G. Cheng, M.E. Lauer, M. Sharma, K. Mikecz, V.C. Hascall, M.A. Aronica, TSG-6 protein is crucial for the development of pulmonary hyaluronan deposition, eosinophilia, and airway hyperresponsiveness in a murine model of asthma., J. Biol. Chem. 288 (2013) 412-22. doi:10.1074/jbc.M112.389874.

[113] M.E. Lauer, A.K. Majors, S. Comhair, L.M. Ruple, B. Matuska, A. Subramanian, C. Farver, R. Dworski, D. Grandon, D. Laskowski, R.A. Dweik, S.C. Erzurum, V.C. Hascall, M.A. Aronica, Hyaluronan and its heavy chain modification in asthma severity and experimental asthma exacerbation., J. Biol. Chem. 290 (2015) 23124-34. doi:10.1074/jbc.M115.663823.

[114] M.E. Lauer, M. Aytekin, S.A. Comhair, J. Loftis, L. Tian, C.F. Farver, V.C. Hascall, R.A. Dweik, Modification of hyaluronan by heavy chains of inter- $\alpha$-inhibitor in idiopathic pulmonary arterial hypertension., J. Biol. Chem. 289 (2014) 6791-8. doi:10.1074/jbc.M113.512491.

[115] A.C. Midgley, M. Rogers, M.B. Hallett, A. Clayton, T. Bowen, A.O. Phillips, R. Steadman, Transforming growth factor- $\beta 1$ (TGF- $\beta 1$ )-stimulated fibroblast to myofibroblast differentiation is mediated by hyaluronan (HA)-facilitated epidermal growth factor receptor (EGFR) and CD44 co-localization in lipid rafts., J. Biol. Chem. 288 (2013) 14824-38. doi:10.1074/jbc.M113.451336.

[116] M.S. Lord, A.J. Day, P. Youssef, L. Zhuo, H. Watanabe, B. Caterson, J.M. Whitelock, Sulfation of the bikunin chondroitin sulfate chain determines heavy chain-hyaluronan complex formation., J. Biol. Chem. 288 (2013) 22930-41. doi:10.1074/jbc.M112.404186.

[117] K.W. Sanggaard, C. Scavenius, A.J. Rasmussen, H.-G. Wisniewski, I.B. Thøgersen, J.J. Enghild, The TSG-6/HC2-mediated transfer is a dynamic process shuffling heavy chains between glycosaminoglycans., J. Biol. Chem. $285 \quad$ (2010) 21988-93. doi:10.1074/jbc.M109.041046.

[118] M.E. Lauer, T.T. Glant, K. Mikecz, P.L. DeAngelis, F.M. Haller, M.E. Husni, V.C. Hascall, A. Calabro, Irreversible heavy chain transfer to hyaluronan oligosaccharides by tumor necrosis 
factor-stimulated gene-6., J. Biol. Chem. 288 (2013) 205-14. doi:10.1074/jbc.M112.403998.

[119] K.W. Sanggaard, C.S. Sonne-Schmidt, T.P. Krogager, K.A. Lorentzen, H.-G. Wisniewski, I.B. Thøgersen, J.J. Enghild, The transfer of heavy chains from bikunin proteins to hyaluronan requires both TSG-6 and HC2., J. Biol. Chem. 283 (2008) 18530-7. doi:10.1074/jbc.M800874200.

[120] K.W. Sanggaard, H. Karring, Z. Valnickova, I.B. Thøgersen, J.J. Enghild, The TSG-6 and I alpha I interaction promotes a transesterification cleaving the protein-glycosaminoglycanprotein (PGP) cross-link., J. Biol. Chem. $280 \quad$ (2005) 11936-42. doi:10.1074/jbc.M409016200.

[121] S.A. Kuznetsova, P. Issa, E.M. Perruccio, B. Zeng, J.M. Sipes, Y. Ward, N.T. Seyfried, H.L. Fielder, A.J. Day, T.N. Wight, D.D. Roberts, Versican-thrombospondin-1 binding in vitro and colocalization in microfibrils induced by inflammation on vascular smooth muscle cells., J. Cell Sci. 119 (2006) 4499-509. doi:10.1242/jcs.03171.

[122] S.A. Kuznetsova, D.J. Mahoney, G. Martin-Manso, T. Ali, H.A. Nentwich, J.M. Sipes, B. Zeng, T. Vogel, A.J. Day, D.D. Roberts, TSG-6 binds via its CUB_C domain to the cellbinding domain of fibronectin and increases fibronectin matrix assembly., Matrix Biol. 27 (2008) 201-10. doi:10.1016/j.matbio.2007.10.003.

[123] D. Leali, A. Inforzato, R. Ronca, R. Bianchi, M. Belleri, D. Coltrini, E. Di Salle, M. Sironi, G.D. Norata, B. Bottazzi, C. Garlanda, A.J. Day, M. Presta, Long pentraxin 3/tumor necrosis factor-stimulated gene-6 interaction: a biological rheostat for fibroblast growth factor 2mediated angiogenesis., Arterioscler. Thromb. Vasc. Biol. 32 (2012) 696-703. doi:10.1161/ATVBAHA.111.243998.

[124] S.A. Kuznetsova, A.J. Day, D.J. Mahoney, M.S. Rugg, D.F. Mosher, D.D. Roberts, The Nterminal module of thrombospondin-1 interacts with the link domain of TSG-6 and enhances its covalent association with the heavy chains of inter-alpha-trypsin inhibitor., J. Biol. Chem. 280 (2005) 30899-908. doi:10.1074/jbc.M500701200.

[125] D.P. Dyer, J.M. Thomson, A. Hermant, T.A. Jowitt, T.M. Handel, A.E.I. Proudfoot, A.J. Day, C.M. Milner, TSG-6 inhibits neutrophil migration via direct interaction with the chemokine CXCL8., J. Immunol. 192 (2014) 2177-85. doi:10.4049/jimmunol.1300194. 
[126] T. V Cao, M. La, S.J. Getting, A.J. Day, M. Perretti, Inhibitory effects of TSG-6 Link module on leukocyte-endothelial cell interactions in vitro and in vivo., Microcirculation. 11 (n.d.) 61524. doi:10.1080/10739680490503438.

[127] J.Y. Oh, G.W. Roddy, H. Choi, R.H. Lee, J.H. Ylöstalo, R.H. Rosa, D.J. Prockop, Antiinflammatory protein TSG-6 reduces inflammatory damage to the cornea following chemical and mechanical injury., Proc. Natl. Acad. Sci. U. S. A. 107 (2010) 16875-80. doi:10.1073/pnas.1012451107.

[128] J.Y. Oh, R.H. Lee, J.M. Yu, J.H. Ko, H.J. Lee, A.Y. Ko, G.W. Roddy, D.J. Prockop, Intravenous mesenchymal stem cells prevented rejection of allogeneic corneal transplants by aborting the early inflammatory response., Mol. Ther. 20 (2012) 2143-2152. doi:10.1038/MT.2012.165.

[129] L. Liu, Y. Yu, Y. Hou, J. Chai, H. Duan, W. Chu, H. Zhang, Q. Hu, J. Du, Human umbilical cord mesenchymal stem cells transplantation promotes cutaneous wound healing of severe burned rats., PLoS One. 9 (2014) e88348. doi:10.1371/journal.pone.0088348.

[130] J. Watanabe, A.K. Shetty, B. Hattiangady, D.-K. Kim, J.E. Foraker, H. Nishida, D.J. Prockop, Administration of TSG-6 improves memory after traumatic brain injury in mice., Neurobiol. Dis. 59 (2013) 86-99. doi:10.1016/J.NBD.2013.06.017.

[131] E. Sala, M. Genua, L. Petti, A. Anselmo, V. Arena, J. Cibella, L. Zanotti, S. D’Alessio, F. Scaldaferri, G. Luca, I. Arato, R. Calafiore, A. Sgambato, S. Rutella, M. Locati, S. Danese, S. Vetrano, Mesenchymal stem cells reduce colitis in mice via release of TSG6, independently of their Localization to the intestine., Gastroenterology. 149 (2015) 163176.e20. doi:10.1053/J.GASTRO.2015.03.013.

[132] A.J. Hertsenberg, G. Shojaati, M.L. Funderburgh, M.M. Mann, Y. Du, J.L. Funderburgh, Corneal stromal stem cells reduce corneal scarring by mediating neutrophil infiltration after wounding., PLoS One. 12 (2017) e0171712. doi:10.1371/journal.pone.0171712.

[133] Y. Qi, D. Jiang, A. Sindrilaru, A. Stegemann, S. Schatz, N. Treiber, M. Rojewski, H. Schrezenmeier, S. Vander Beken, M. Wlaschek, M. Böhm, A. Seitz, N. Scholz, L. Dürselen, J. Brinckmann, A. Ignatius, K. Scharffetter-Kochanek, TSG-6 released from intradermally injected mesenchymal stem cells accelerates wound healing and reduces tissue fibrosis in 
murine full-thickness skin wounds., J. Invest. Dermatol. 134 (2014) 526-537. doi:10.1038/JID.2013.328.

[134] S. Jin Kim, H. Ju Lee, J.-H. Yun, J. Hwa Ko, D.Y. Choi, J. Youn Oh, Intravitreal TSG-6 suppresses laser-induced choroidal neovascularization by inhibiting CCR2+ monocyte recruitment., Sci. Rep. 5 (2015) 11872. doi:10.1038/srep11872.

[135] I. Inoue, R. Ikeda, S. Tsukahara, Current Topics in Pharmacological Research on Bone Metabolism: Promyelotic Leukemia Zinc Finger (PLZF) and Tumor Necrosis Factor- $\alpha-$ Stimulated Gene 6 (TSG-6) identified by gene expression analysis play roles in the pathogenesis of ossification of the posterior longitudinal ligament., J. Pharmacol. Sci. 100 (2006) 205-210. doi:10.1254/jphs.FMJ05004X5.

[136] S. Tsukahara, R. Ikeda, S. Goto, K. Yoshida, R. Mitsumori, Y. Sakamoto, A. Tajima, T. Yokoyama, S. Toh, K. Furukawa, I. Inoue, Tumour necrosis factor alpha-stimulated gene-6 inhibits osteoblastic differentiation of human mesenchymal stem cells induced by osteogenic differentiation medium and BMP-2., Biochem. J. 398 (2006) 595-603. doi:10.1042/BJ20060027.

[137] D.J. Mahoney, K. Mikecz, T. Ali, G. Mabilleau, D. Benayahu, A. Plaas, C.M. Milner, A.J. Day, A. Sabokbar, TSG-6 regulates bone remodeling through inhibition of osteoblastogenesis and osteoclast activation., J. Biol. Chem. 283 (2008) 25952-62. doi:10.1074/jbc.M802138200.

[138] S. Um, H.Y. Kim, J.-H. Lee, I.-S. Song, B.M. Seo, TSG-6 secreted by mesenchymal stem cells suppresses immune reactions influenced by BMP-2 through p38 and MEK mitogenactivated protein kinase pathway., Cell Tissue Res. 368 (2017) 551-561. doi:10.1007/s00441-017-2581-4.

[139] S. Wang, S. Hu, Q. Zhang, A. Xia, Z. Jiang, X. Chen, Mesenchymal stem cells stabilize atherosclerotic vulnerable plaque by anti-inflammatory properties., PLoS One. 10 (2015) e0136026. doi:10.1371/journal.pone.0136026.

[140] R. Watanabe, H. Watanabe, Y. Takahashi, M. Kojima, H. Konii, K. Watanabe, R. Shirai, K. Sato, T. Matsuyama, H. Ishibashi-Ueda, Y. Iso, S. Koba, Y. Kobayashi, T. Hirano, T. Watanabe, Atheroprotective effects of Tumor Necrosis Factor-Stimulated Gene-6., JACC 
Basic to Transl. Sci. 1 (2016) 494-509. doi:10.1016/J.JACBTS.2016.07.008.

[141] C. Zhang, B. Zhang, H. Wang, Q. Tao, S. Ge, Z. Zhai, Tumor necrosis factor alphastimulated gene-6 (TSG-6) inhibits the inflammatory response by inhibiting the activation of P38 and JNK signaling pathway and decreases the restenosis of vein grafts in rats., Heart Vessels. 32 (2017) 1536-1545. doi:10.1007/s00380-017-1059-3.

[142] H. Wang, Z. Chen, X.-J. Li, L. Ma, Y.-L. Tang, Anti-inflammatory cytokine TSG-6 inhibits hypertrophic scar formation in a rabbit ear model., Eur. J. Pharmacol. 751 (2015) 42-49. doi:10.1016/J.EJPHAR.2015.01.040.

[143] S.R. Beltran, K.K.H. Svoboda, D.G. Kerns, A. Sheth, D.J. Prockop, Anti-Inflammatory protein tumor necrosis factor-a-stimulated protein 6 (TSG-6) promotes early gingival wound healing: an in vivo study., J. Periodontol. 86 (2015) 62-71. doi:10.1902/jop.2014.140187.

[144] J. Tuo, X. Cao, D. Shen, Y. Wang, J. Zhang, J.Y. Oh, D.J. Prockop, C.-C. Chan, Antiinflammatory recombinant TSG-6 stabilizes the progression of focal retinal degeneration in a murine model., J. Neuroinflammation. 9 (2012) 59. doi:10.1186/1742-2094-9-59.

[145] S. Wang, J.-S. Lee, J. Hyun, J. Kim, S.U. Kim, H.-J. Cha, Y. Jung, Tumor necrosis factorinducible gene 6 promotes liver regeneration in mice with acute liver injury., Stem Cell Res. Ther. 6 (2015) 20. doi:10.1186/s13287-015-0019-z.

[146] C. Mindrescu, G.J. Thorbecke, M.J. Klein, J. Vilček, H.-G. Wisniewski, Amelioration of collagen-induced arthritis in DBA/1J mice by recombinant TSG-6, a tumor necrosis factor/interleukin-1-inducible protein., Arthritis Rheum. $43 \quad$ (2000) 2668-2677. doi:10.1002/1529-0131(200012)43:12<2668::AID-ANR6>3.0.CO;2-E.

[147] T. Bárdos, R. V. Kamath, K. Mikecz, T.T. Glant, Anti-Inflammatory and chondroprotective effect of TSG-6 (Tumor Necrosis Factor- $\alpha-S t i m u l a t e d ~ G e n e-6)$ in murine models of experimental arthritis., Am. J. Pathol. 159 (2001) 1711-1721. doi:10.1016/S00029440(10)63018-0.

[148] R. Zhang, Y. Liu, K. Yan, L. Chen, X.-R. Chen, P. Li, F.-F. Chen, X.-D. Jiang, Antiinflammatory and immunomodulatory mechanisms of mesenchymal stem cell transplantation in experimental traumatic brain injury., J. Neuroinflammation. 10 (2013) 871. doi:10.1186/1742-2094-10-106. 
[149] R.H. Lee, J.M. Yu, A.M. Foskett, G. Peltier, J.C. Reneau, N. Bazhanov, J.Y. Oh, D.J. Prockop, TSG-6 as a biomarker to predict efficacy of human mesenchymal stem/progenitor cells (hMSCs) in modulating sterile inflammation in vivo., Proc. Natl. Acad. Sci. U. S. A. 111 (2014) 16766-71. doi:10.1073/pnas.1416121111.

[150] E.M. Amann, M.T. Rojewski, S. Rodi, D. Fürst, J. Fiedler, A. Palmer, S. Braumüller, M. Huber-Lang, H. Schrezenmeier, R.E. Brenner, Systemic recovery and therapeutic effects of transplanted allogenic and xenogenic mesenchymal stromal cells in a rat blunt chest trauma model., Cytotherapy. (2017). doi:10.1016/j.jcyt.2017.11.005.

[151] S. Wang, C. Lee, J. Kim, J. Hyun, M. Lim, H.-J. Cha, S.-H. Oh, Y.H. Choi, Y. Jung, Tumor necrosis factor-inducible gene 6 protein ameliorates chronic liver damage by promoting autophagy formation in mice., Exp. Mol. Med. 49 (2017) e380. doi:10.1038/emm.2017.140.

[152] Y. Liu, R. Zhang, K. Yan, F. Chen, W. Huang, B. Lv, C. Sun, L. Xu, F. Li, X. Jiang, Mesenchymal stem cells inhibit lipopolysaccharide-induced inflammatory responses of BV2 microglial cells through TSG-6., J. Neuroinflammation. 11 (2014) 135. doi:10.1186/17422094-11-135.

[153] Z. He, J. Hua, D. Qian, J. Gong, S. Lin, C. Xu, G. Wei, H. Meng, T. Yang, B. Zhou, Z. Song, Intravenous hMSCs ameliorate acute pancreatitis in mice via secretion of Tumor Necrosis Factor- $\alpha$ Stimulated Gene/Protein 6., Sci. Rep. 6 (2016) 38438. doi:10.1038/srep38438.

[154] L. Kui, G.C. Chan, P.P.W. Lee, TSG-6 downregulates IFN-Alpha and TNF-Alpha expression by suppressing IRF7 phosphorylation in human plasmacytoid dendritic cells., Mediators Inflamm. 2017 (2017) 7462945. doi:10.1155/2017/7462945.

[155] H.A. Nentwich, Z. Mustafa, M.S. Rugg, B.D. Marsden, M.R. Cordell, D.J. Mahoney, S.C. Jenkins, B. Dowling, E. Fries, C.M. Milner, J. Loughlin, A.J. Day, A novel allelic variant of the human TSG-6 gene encoding an amino acid difference in the CUB module. Chromosomal localization, frequency analysis, modeling, and expression., J. Biol. Chem. 277 (2002) 15354-62. doi:10.1074/jbc.M110765200.

[156] D.C. Briggs, A.J. Day, A bug in CUB's clothing: similarity between clostridial CBMs and complement CUBs, Trends Microbiol. 16 (2008) 407-408. doi:10.1016/j.tim.2008.06.002.

[157] A. Kaczmarczyk, M. Thuveson, E. Fries, Intracellular coupling of the heavy chain of pre- 
alpha-inhibitor to chondroitin sulfate., J. Biol. Chem. 277 (2002) 13578-82. doi:10.1074/jbc.M200288200.

[158] K.W. Sanggaard, C.S. Sonne-Schmidt, T.P. Krogager, T. Kristensen, H.-G. Wisniewski, I.B. Thøgersen, J.J. Enghild, TSG-6 transfers proteins between glycosaminoglycans via a Ser28-mediated covalent catalytic mechanism., J. Biol. Chem. 283 (2008) 33919-26. doi:10.1074/jbc.M804240200.

[159] M.J. Lee, D.H. Kim, J.S. Ryu, A.Y. Ko, J.H. Ko, M.K. Kim, W.R. Wee, S.I. Khwarg, J.Y. Oh, Topical TSG-6 administration protects the ocular surface in two mouse models of inflammation-related dry eye., Investig. Opthalmology Vis. Sci. 56 (2015) 5175. doi:10.1167/iovs.14-16307.

[160] Y.J. Kim, J.S. Ryu, S.Y. Park, H.J. Lee, J.H. Ko, M.K. Kim, W.R. Wee, J.Y. Oh, Comparison of topical application of TSG-6, cyclosporine, and prednisolone for treating dry eye., Cornea. 35 (2016) 536-542. doi:10.1097/ico.0000000000000756.

[161] H. Yang, R.M. Aprecio, X. Zhou, Q. Wang, W. Zhang, Y. Ding, Y. Li, Therapeutic effect of TSG-6 engineered iPSC-derived MSCs on experimental periodontitis in rats: a pilot study., PLoS One. 9 (2014) e100285. doi:10.1371/journal.pone.0100285.

[162] G. Di, X. Du, X. Qi, X. Zhao, H. Duan, S. Li, L. Xie, Q. Zhou, Mesenchymal stem cells promote diabetic corneal epithelial wound healing through TSG-6-dependent stem cell activation and macrophage switch., Investig. Opthalmology Vis. Sci. 58 (2017) 4344. doi:10.1167/iovs.17-21506. 
Table 1 - The Ligand-Binding Properties of Human TSG-6

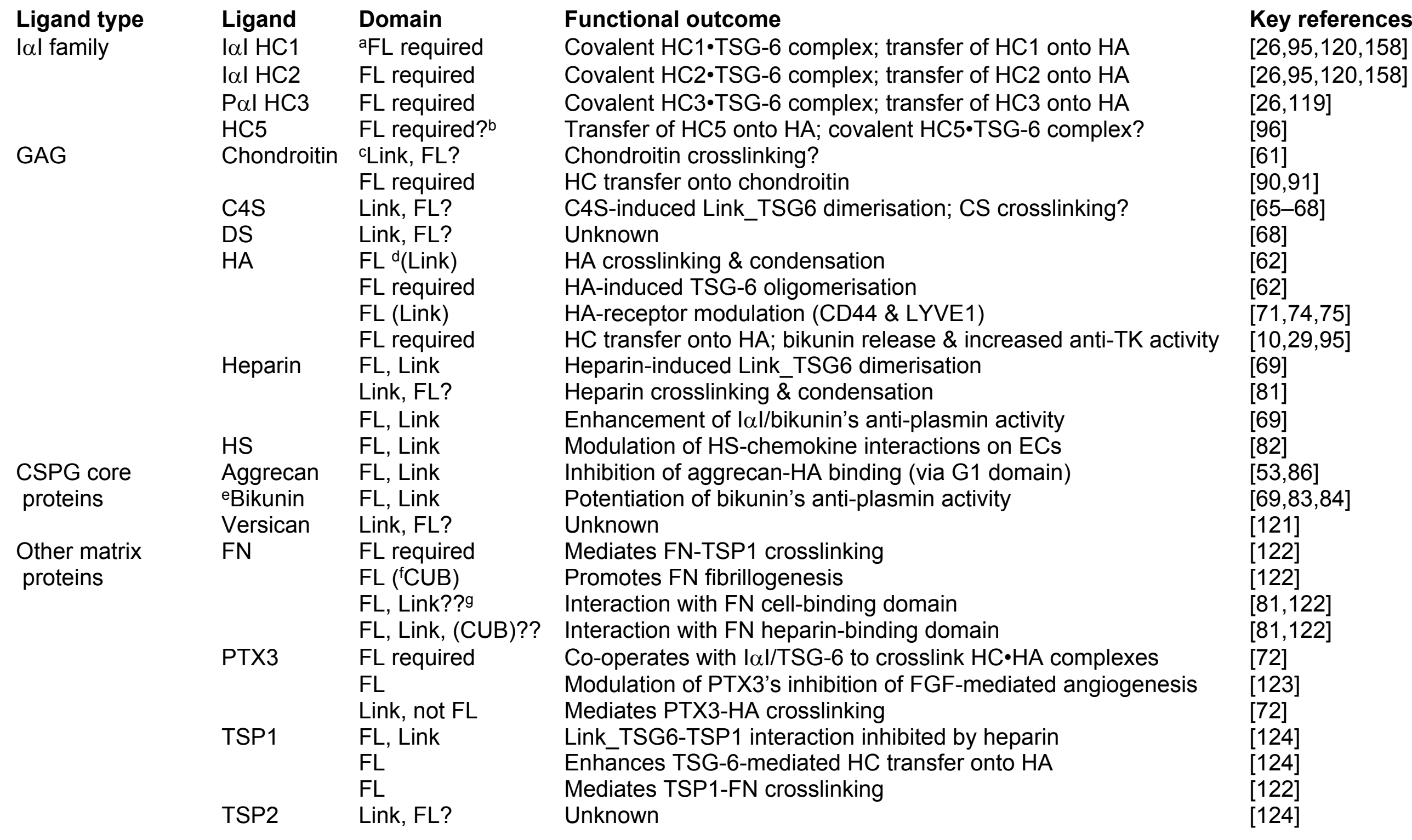




\section{Table 1 continued}

Ligand type

Chemokines

$\begin{array}{ll}\text { CCL5 } & \text { Link, FL? } \\ \text { CCL7 } & \text { Link, FL? } \\ \text { CCL19 } & \text { Link, FL? } \\ \text { CCL21 } & \text { Link, FL? } \\ & \\ \text { CCL27 } & \text { Link, FL? } \\ \text { CXCL4 } & \text { Link, FL? } \\ \text { CXCL8 } & \text { FL, Link } \\ & \\ \text { CXCL11 } & \text { FL, Link } \\ \text { CXCL12 } & \text { Link, FL? }\end{array}$

Growth factors BMP2

BMP4

BMP5

BMP6

BMP7

BMP13

BMP14

Tryptases

\section{RANKL}

mMCP-6 mMCP-7

\section{Domain}

Link, FL?

ink, FL?

ink, FL?

ink, FL?

Link, FL?

FL (Link, CUB??)

$\mathrm{FL}$

FL

FL

FL

FL (Link, CUB)

FL (Link, CUB)

FL (Link, CUB)

FL

FL

\section{Functional outcome}

Inhibits CCL2-heparin binding \& CCL2-HS interaction on ECs

Inhibits CCL5-HS interaction on ECs

Inhibits CCL7-heparin binding \& CCL7-HS interaction on ECs

Inhibits CCL19-heparin binding \& CCL19-mediated transmigration

Inhibits CCL21-HS interaction on ECs;

Inhibits CCL21-mediated adhesion \& transmigration;

Inhibits CCL21 binding to type I collagen

Unknown

Inhibits CXCL4-HS interaction on ECs

Inhibits CXCL4 binding to type I collagen

Inhibits CXCL8-heparin binding \& CXCL8-HS interaction on ECs

Inhibits CXCL8-mediated chemotaxis \& transmigration

Inhibits CXCL11-heparin binding

Inhibits CXCL12-HS interaction on ECs

Inhibits CXCL12 binding to type I collagen

Key references

[82]

$[82,125]$

[82]

[82]

[82]

[82]

[82]

[82]

[82]

[82]

[125]

[125]

$[82,125]$

Inhibition of BMP2-mediated osteoblast formation

Unknown

[82]

$[136,137]$

Unknown

Unknown

Unknown

Unknown

Unknown

Inhibition of RANKL-mediated osteoclast activation?

Unknown. Stored with TSG-6 \& heparin in mast cell granules

Unknown. Stored with TSG-6 \& heparin in mast cell granules
[137]

[137]

[137]

[137]

[137]

[137]

aFL = full-length TSG-6; $?^{\mathrm{b}}=$ data not available, but interaction with this domain would be anticipated; 'Link = Link module of TSG-6 (Link_TSG6); ${ }^{\mathrm{d}}()=$ binding or functional effect weaker than for full-length TSG-6; eBikunin = CSPG that forms part of l $\alpha \mathrm{l}$ and P $\alpha$ l; ${ }^{\mathrm{f} C U B}=$ CUB_C_TSG6; ??g = data in literature is conflicting 
Table 2 - Summary of TSG-6 Expression in Cells and Tissues

\section{Tissue/cell type}

Amniotic membrane

Brain, spinal cord

Lung

Pancreas

Skin
Abnominal aorta
Cumulus cells

Endometrium

Articular joint

Cartilage

Synovial fluid

MSCs (BM)

MSCs (AD)

MSCs (DFAT)

MSCs (UCPV)

Mast cells

Neutrophils

DCs

Macrophages

Monocytes

Osteoclasts

\section{Species \\ Constitutive expression}

Human

Rat

Human

Human

Mouse

Mouse

Mouse

Human

Human

Mouse

Human

Human

Mouse

Human

Human

Human

Human

Human

Human

Human

Mouse

Human

Human

Human

Human

Human
$\mathrm{P}$; islets of Langerhans

bP/R; epithelial \& stromal cells

$\mathrm{P} / \mathrm{R} ; \mathrm{CD} 44^{+} / \mathrm{GFAP}^{+}$astrocytes

$\mathrm{P}$; tracheal aspirates

$\mathrm{P}$; islets of Langerhans

$\mathrm{P} / \mathrm{R}$; islet $\alpha \& \beta$ cells

$\mathrm{P} / \mathrm{R}$; islet cells

$\mathrm{P}$; epidermis, dermis

$P$; hair follicles \& SG

P/R; 3D spheroids

$\mathrm{P} / \mathrm{R}$; monolayer

$\mathrm{P}$; secretory granules

$\mathrm{P} / \mathrm{R}$; secretory granules

\section{${ }^{\text {aAltered expression (stimulus) }}$}

$P / R$; glial scar after spinal cord injury

$P$; tracheal aspirates from smokers

$\mathrm{P}$ : BAL from asthma patients (allergen)

$\mathrm{R}$; submucosal gland cells (IL-1, TNF)

$\mathrm{R}$; airway epithelial cells (IL-1, TNF)

$P$; decreased in insultitis \& T1D

$P$; immune cells in insulitis \& T1D

$\mathrm{P}$; decreased in prediabetes/diabetes

$\mathrm{P}$; decreased in prediabetes/diabetes

$\mathrm{P}$; decreased in keloid scars

P/R; VSMCs \& perivascular cells in aneurysm [46]

P/R; prostaglandins \& FSH during ovulation $\quad[28,30]$

$\mathrm{P} / \mathrm{R}$; menstrual cycle (TNF) [47]

$\mathrm{P} / \mathrm{R}$; endometriosis [48]

$P$; joint trauma [55]

$\mathrm{R}$; joint destabilisation

P/R; OA

P: Gout, OA, PA, PPA, RA

$[50-53,87]$

$\mathrm{P} / \mathrm{R}$; monolayer (TNF)

$[45,53]$

[36]

P/R; monolayer (IL-1/TNF)

$\mathrm{P} / \mathrm{R}$; monolayer (TNF); coculture with MSs

[37-39]

P/R; monolayer (LPS/TNF); coculture with ICs [41,42]

$P$; inflammatory arthritis

$\mathrm{P} / \mathrm{R} ;($ LPS)

[24]

P/R; (LPS, LPS+IL10)

[24]

$\mathrm{P} / \mathrm{R} ;($ LPS, TNF)

$\mathrm{R} ;($ LPS)

$P ;(I L-1, I L-6, T N F)$ 


\section{Table 2 continued}

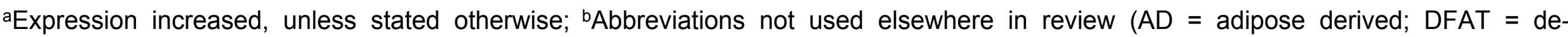
differentiated fat; ICs = inflammatory cells; MCs = mesangial cells; $\mathrm{P}=$ protein; PA = psoriatic arthritis; PPA = pyrophosphate arthritis; $\mathrm{R}=$ mRNA; SG = sebaceous gland; T1D = type-1 diabetes; UCPV = umbilical cord perivascular). 
Table 3 - Therapeutic Effect of TSG-6 in Disease Models

System/Indication

${ }^{a}$ MSC bProtein (route)

\section{Cardiovascular:}

Atherosclerosis

Myocardial infarction

Restenosis

\section{Eye:}

AMD (dry)

Corneal allograft rejection $\checkmark$

Corneal wounding

Dry eye

\section{Gastroenterology:}

Colitis

Peritonitis

$$
\checkmark \text { oe }
$$$$
\text { rhTSG-6 (i.p.) }
$$

rhTSG-6 (i.vit) rhTSG-6 (i.vit) rhTSG-6 (i.v.) rhTSG-6 (a.c.) rhTSG-6 (topical)

\section{Outcome \& mechanism/signalling pathway}

\section{Key references}

Stabilized vulnerable plaques, reduced IL-1, IL-6, TNF, ' $\mathrm{CRP}$ Reduced atherosclerotic lesion \& inflammation in $\mathrm{ApoE}^{-/-}$mice; reduced $\mathrm{M} 1 \mathrm{M} \varnothing$; reduced cholesterol

Reduced infarct size, reduced inflammation \& PMN infiltration

Reduced MØ/SMC proliferation, fibrosis \& cytokine production; inhibition of $\mathrm{p} 38 / \mathrm{JNK}$ signaling

Reduced retinal lesions, reduced IL-17A

Reduced CNV, reduced VEGF, CCL2 \& CCR2 ${ }^{+}$cells (e.g. MØ)

Graft survival prolonged, reduced inflammation \& APC activation

Reduced corneal opacity, vascularization \& PMN infiltration; reduced inflammatory cytokines, chemokines \& MMPs

Reduced epithelial lesions, inflammatory cytokines;

in Sjogren's (NOD.B10 mouse) suppressed Th2 immunity

Reduced colitis, reduced inflammation (cytokines, PMN \&

CD45+ cells); increased regulatory $M 2 M \varnothing$ \& regulatory $T$ cells

Reduced inflammation (reduced NF- $\mathrm{KB}$ ) \& TNF production by M $\varnothing$

\section{Metabolic:}

Acute liver injury

$\checkmark$ oe

Chronic liver damage

Kidney transplant rejection $\checkmark$

Pancreatitis (acute)

rhTSG-6 (i.p.)

rhTSG-6 (i.a.)

rhTSG-6 (i.v.)

Type-1 diabetes

rhTSG-6 (i.v.)
Improved repair; reduced inflammatory cytokines; reduced fibrosis [145]

Reduced liver damage; increased autophagy; decreased apoptosis [151]

Prolonged graft survival; reduced rejection; decreased T cells [37]

Reduced pathology; reduced inflammation (e.g. IL-1, IL-6, TNF) [153]

Delayed onset; inhibited T cell activation;

[79]

increased Tregs \& tolerogenic APCs 


\section{Table 3 continued}

\section{System/Indication}

Musculoskeletal:

Peridonitis

Rheumatoid arthritis

\section{Neurology:}

Traumatic brain injury

\section{Respiratory:}

Acute lung injury:

Bleomycin

Blunt trauma

LPS-induced

\section{Wound Healing:}

Cutaneous (excisional)

Cutaneous (severe burn)

Diabetic corneal wounds

Gingival wound

Hypertrophic scarring
${ }^{a}$ MSC ${ }^{\text {b}}$ Protein (route)

$\checkmark$ oe

rhTSG-6 (i.v.) rmTSG-6 (i.v.)

rhTSG-6 (i.v.)
Outcome \& mechanism/signalling pathway

Reduced bone resorption; reduced inflammation (IL-1, TNF)

Reduced disease incidence, pannus formation \& cartilage erosion [146]

Reduced oedema, cartilage degradation \& bone erosion

Reduced lesion size \& BBB leakage; increased memory \&

new born neurons; reduced PMNs \& MMPs;

improved neurological recovery; reduced NF-kB

rhTSG-6 (i.p.) Reduced inflammation, reduced NF-кB

Reduced injury score, reduced inflammatory cytokines \& cells

rhTSG-6 (tracheal) Increased survival of TSG-6-/- mice; switch of M $\varnothing$ from M1 to M2;

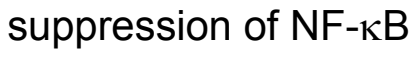

Accelerated healing; reduced fibrosis \& inflammation (TNF);

switch from high to low TGF $\beta 1 /$ TGF $\beta 3$ ratio

Reduced excessive acute local \& systemic inflammation;

inhibited p38/JNK signaling

Improved epithelial healing \& stimulation of corneal MSCs;

reduced inflammation; polarized $\mathrm{M} \varnothing$ to $\mathrm{M} 2$ phenotype

rTSG-6 (i.v.)

rhTSG-6 (s.con)

$\checkmark \quad$ rhTSG-6 (local)

rhTSG-6 (i.d.)
Improved repair; reduced inflammation (cytokines \& PMNs)

Reduced inflammation (cytokines \& PMNs); reduced collagen synthesis
Key references

aMSCs with siRNA knockdown of TSG-6 had lower ameliorative effect, or increased therapeutic activity with TSG-6 overexpression (oe);

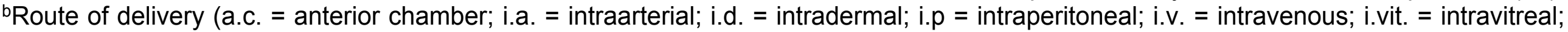
s.con. = subconjunctival) for rhTSG-6 or recombinant mouse TSG-6 (rmTSG-6). ${ }^{\mathrm{c}}$ Abbreviations not used elsewhere in review (APC = 
antigen-presenting cell; BBB = blood-brain barrier; $\mathrm{CNV}=$ choroidal neovascularisation; $\mathrm{CRP}=\mathrm{C}$-reactive protein; $\mathrm{M} \varnothing=$ macrophage; $\mathrm{PMN}=$ polymorphonuclear cell (neutrophil). 

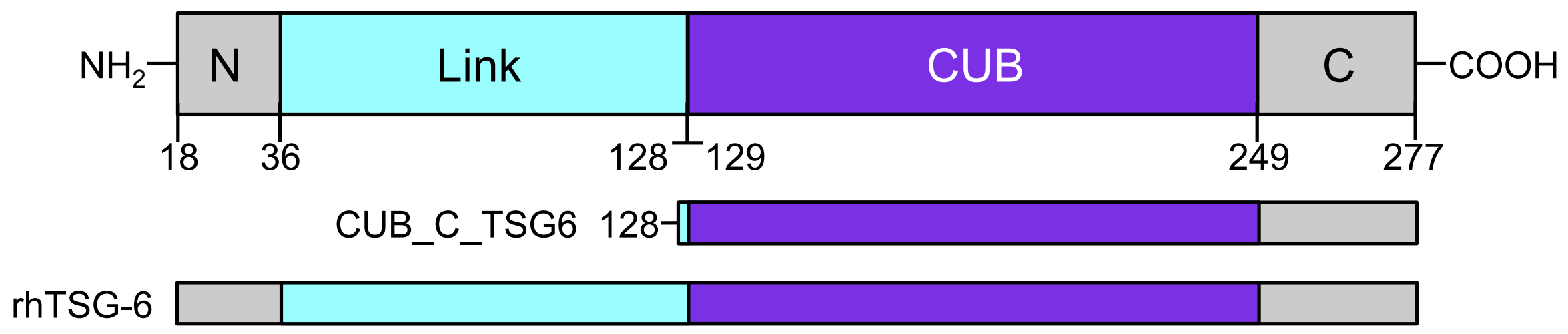

Link_TSG6 36-【
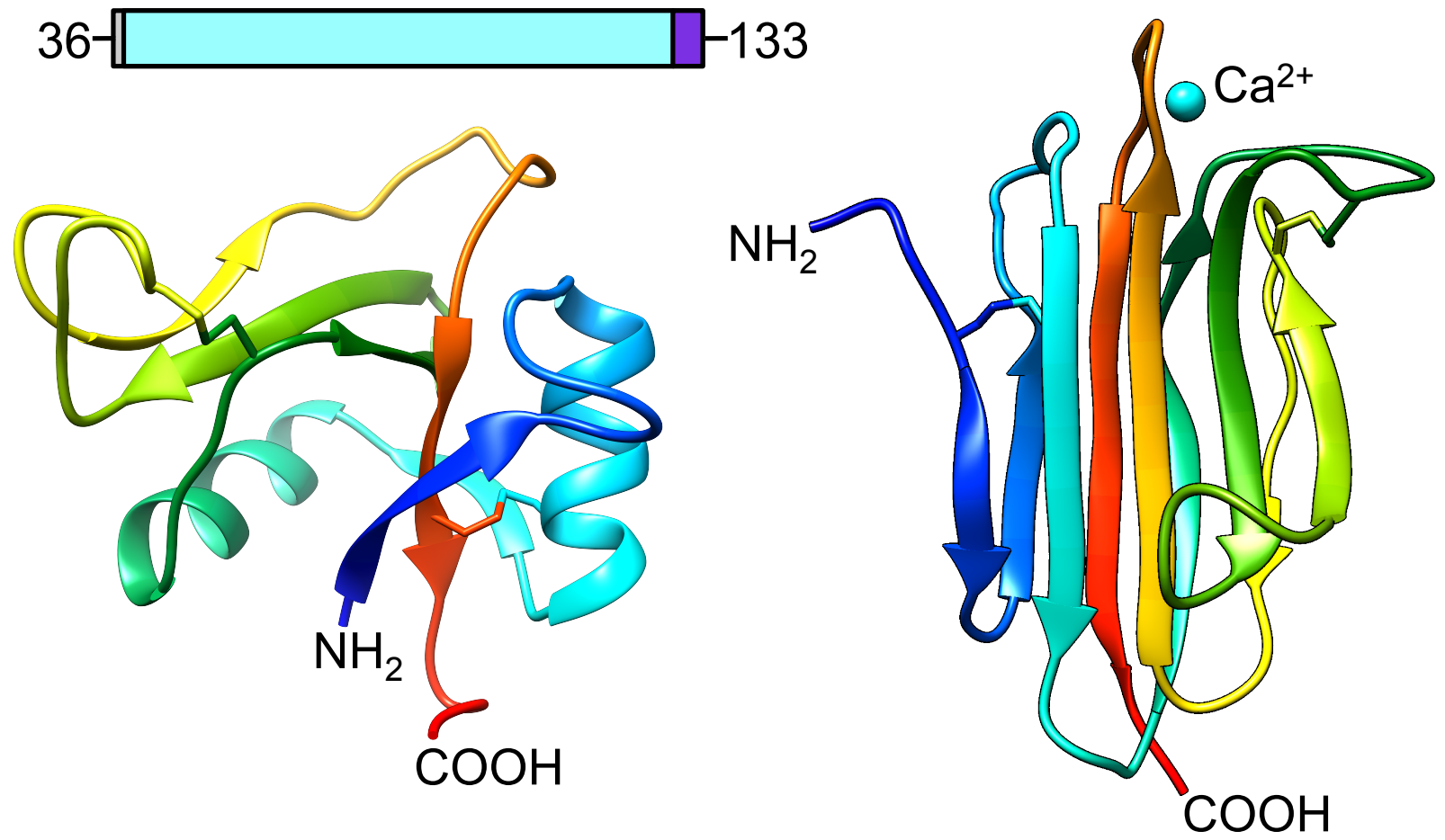
A

B

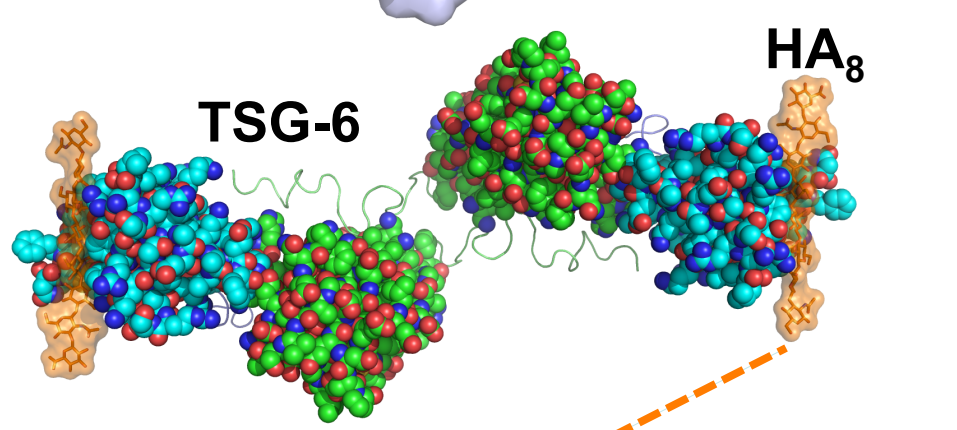

C

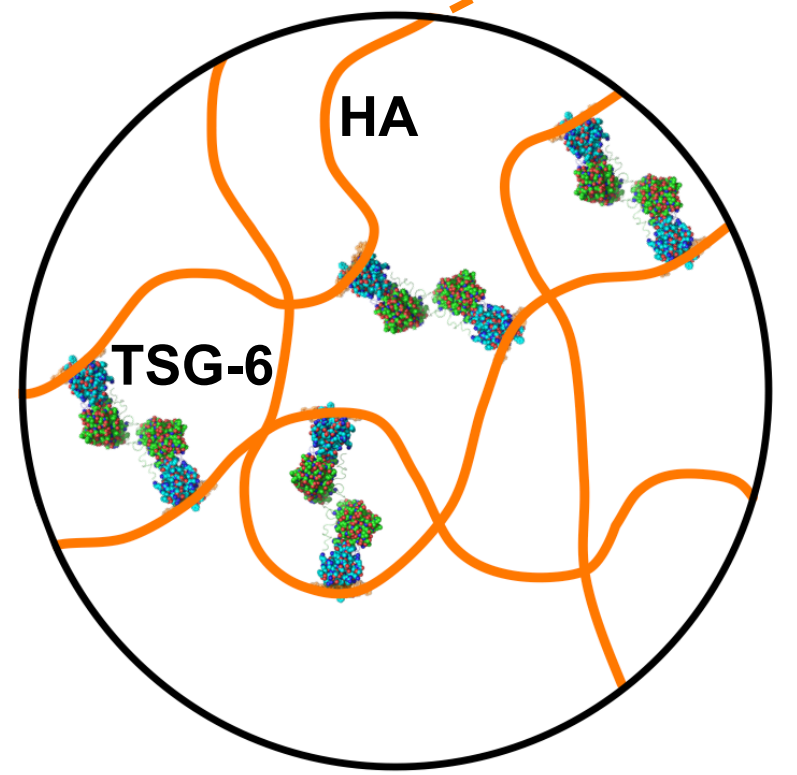

D

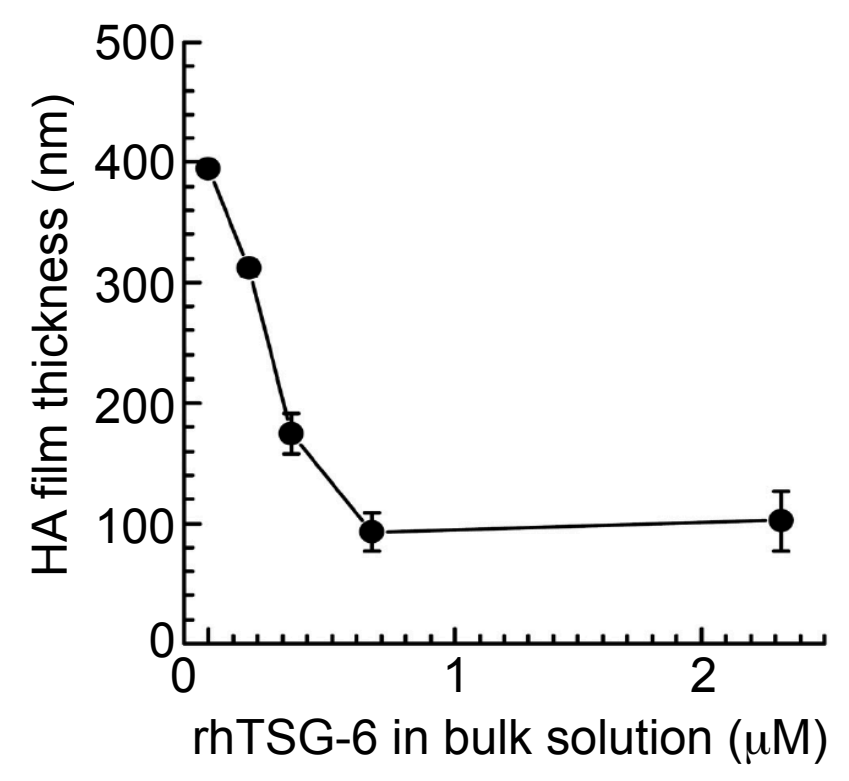

E
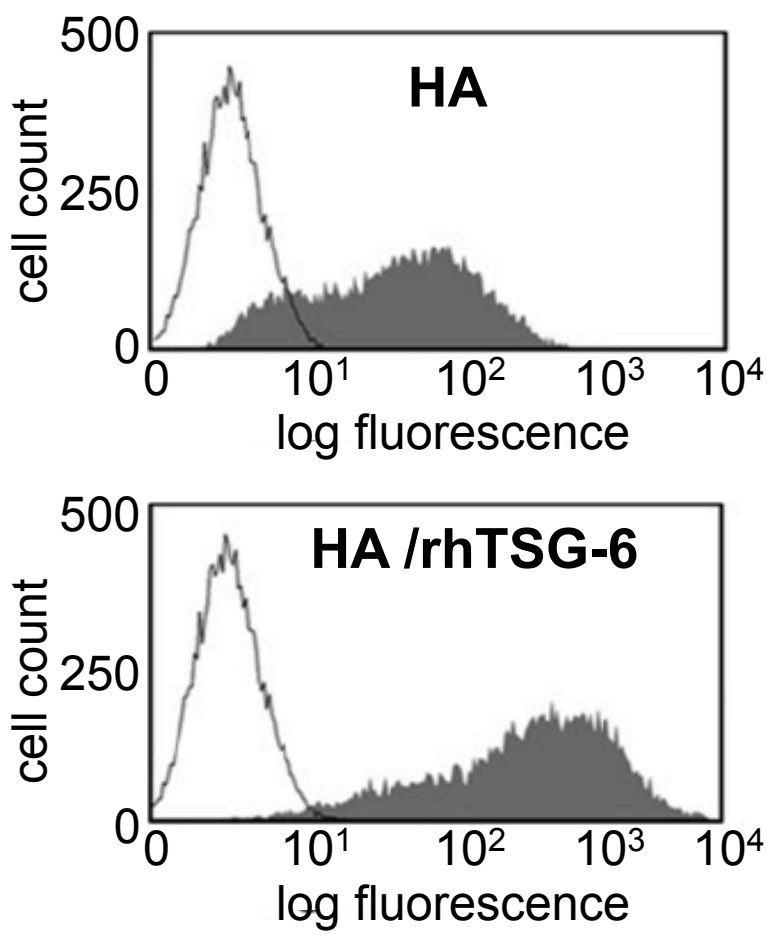


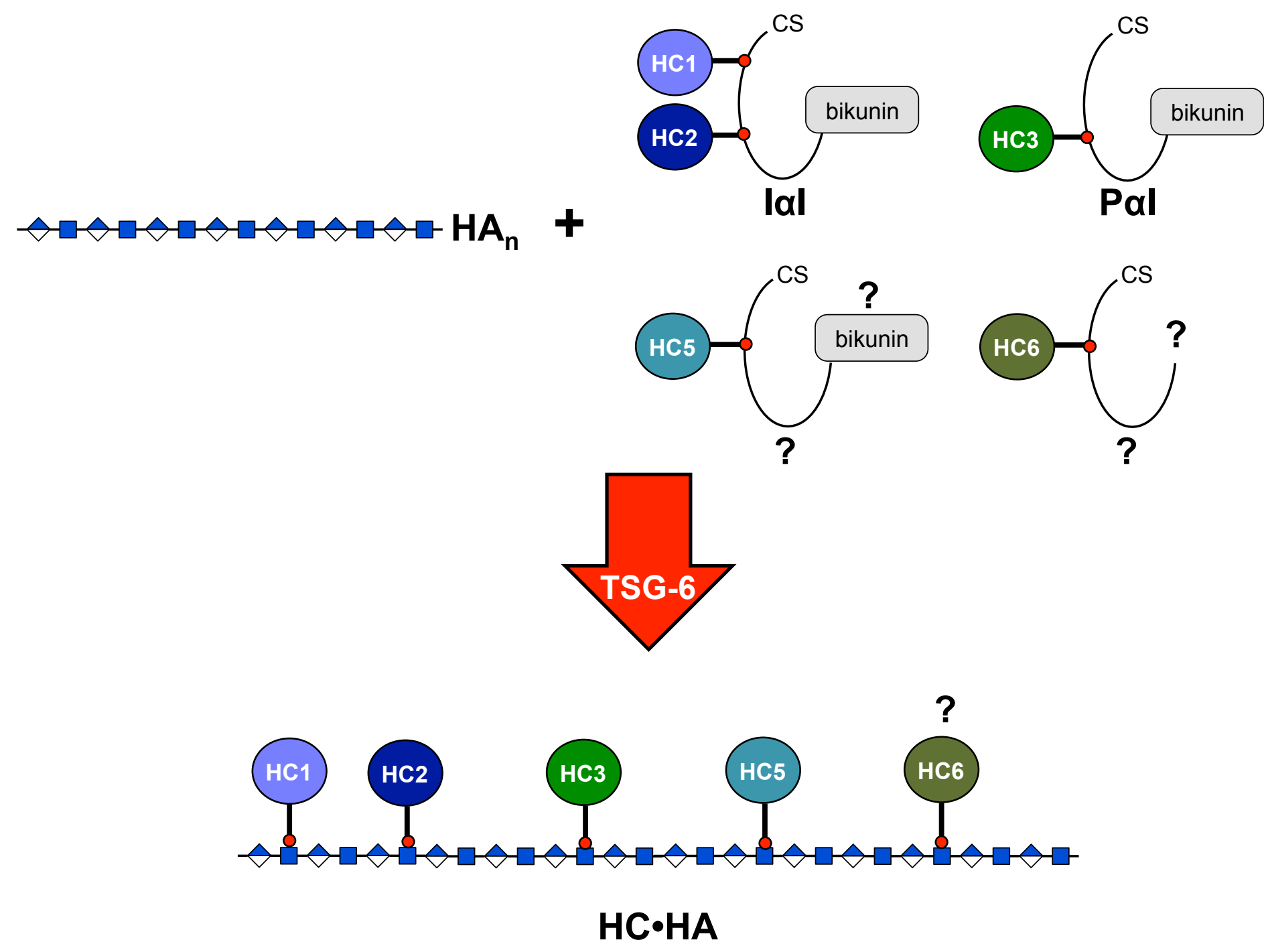


A

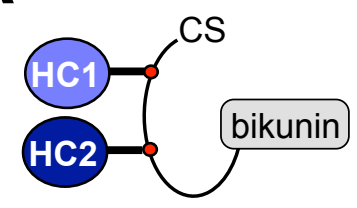

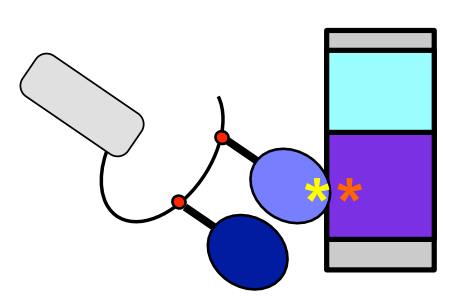

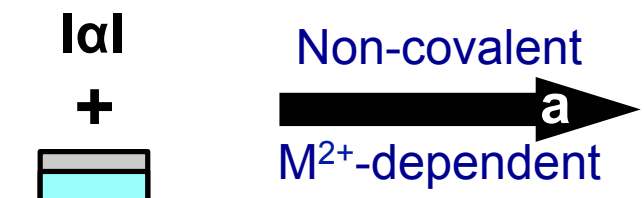

TSG-6

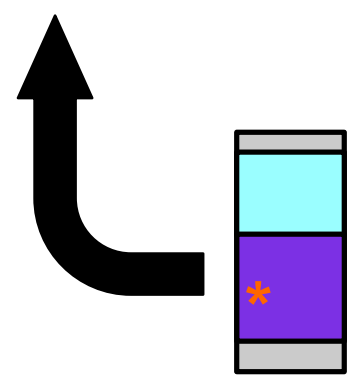

I $\alpha \mid / T S G-6$ complexes

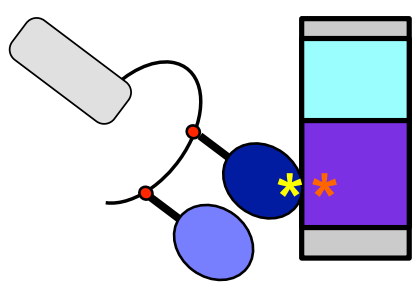

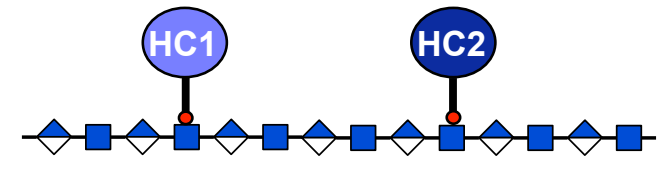

HC.HA

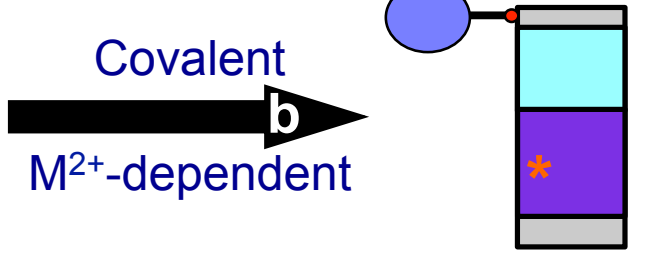

HC.TSG-6 complexes

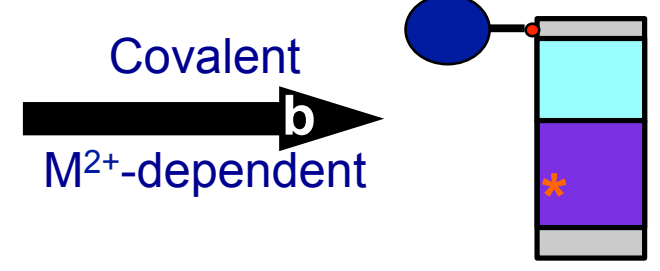

$$
+\mathrm{HA}
$$

B
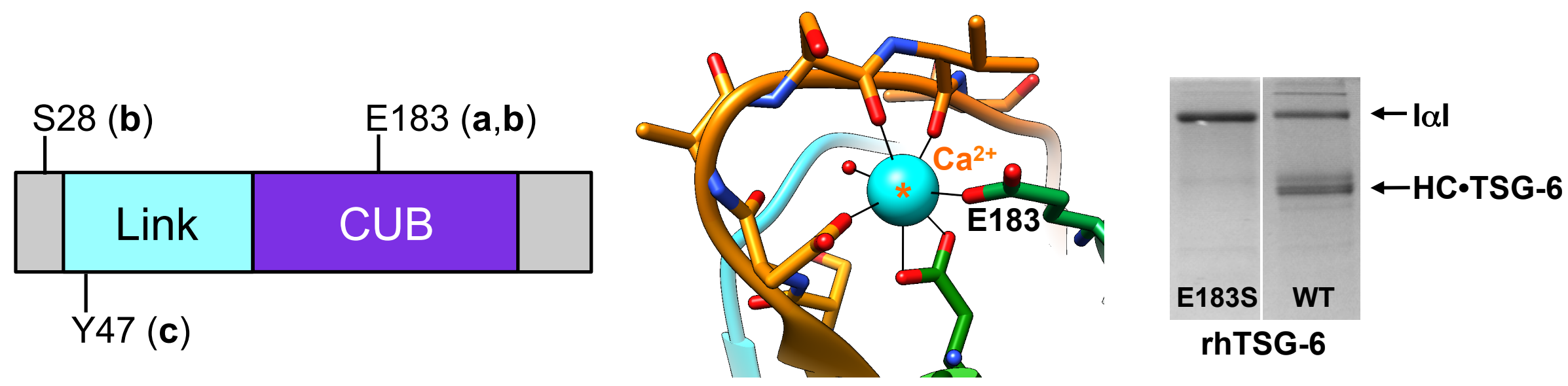